University of Louisville

ThinkIR: The University of Louisville's Institutional Repository

8-2007

\title{
Anxiety disorders in children with Williams syndrome, their mothers, and their siblings : implications for the etiology of anxiety disorders.
}

Ovsanna Leyfer

University of Louisville

Follow this and additional works at: https://ir.library.louisville.edu/etd

\section{Recommended Citation}

Leyfer, Ovsanna, "Anxiety disorders in children with Williams syndrome, their mothers, and their siblings : implications for the etiology of anxiety disorders." (2007). Electronic Theses and Dissertations. Paper 821.

https://doi.org/10.18297/etd/821

This Doctoral Dissertation is brought to you for free and open access by ThinkIR: The University of Louisville's Institutional Repository. It has been accepted for inclusion in Electronic Theses and Dissertations by an authorized administrator of ThinkIR: The University of Louisville's Institutional Repository. This title appears here courtesy of the author, who has retained all other copyrights. For more information, please contact thinkir@louisville.edu. 
ANXIETY DISORDERS IN CHILDREN WITH WILLIAMS SYNDROME, THEIR MOTHERS, AND THEIR SIBLINGS: IMPLICATIONS FOR THE ETIOLOGY OF ANXIETY DISORDERS

By

Ovsanna Leyfer

B.A., Allegheny College, 1998

M.A., Tufts University, 2001

M.A., University of Louisville, 2005

\author{
A Dissertation \\ Submitted to the Faculty of the \\ Graduate School of the University of Louisville \\ in Partial Fulfillment of the Requirements \\ for the Degree of \\ Doctor of Philosophy \\ Department of Psychological and Brain Sciences \\ University of Louisville \\ Louisville, KY
}

August 2007 
Copyright 2006 by Ovsanna Leyfer

All rights reserved 
ANXIETY DISORDERS IN CHILDREN WITH WILLIAMS SYNDROME, THEIR MOTHERS, AND THEIR SIBLINGS: IMPLICATIONS FOR THE ETIOLOGY OF ANXIETY DISORDERS

\author{
By \\ Ovsanna Leyfer \\ B.A., Allegheny College, 1999 \\ M.A., Tufts University, 2001 \\ M.A., University of Louisville, 2005 \\ A Dissertation Approved on
}

October 16, 2006

By the following Dissertation Committee:

Janet Woodruff-Borden, Ph.D.

Dissertation Advisor

Carolyn B. Mervis, Ph.D.

Dissertation Co-advisor

Paul G. Salmon, Ph.D.

Benjamin T. Mast, Ph.D.

Deborah W. Davis, D.N.S.

Doris J. Kistler, Ph.D. 


\section{ACKNOWLEDGMENTS}

This research was supported by grant \#NS35102 from the National Institute of Neurological Disorders and Stroke and grant \# H829957 from the National Institute of Child Health and Human Development to Dr. Carolyn Mervis.

I wish to express my gratitude to the people who made this dissertation project possible:

Dr. Janet Woodruff-Borden and Dr. Carolyn Mervis, my advisors and mentors, who guided me through every day of my graduate career, providing wonderful mentorship, encouragement, and unsurpassed support as well as help with data collection.

Dr. Deborah Davis, Dr. Doris Kistler, Dr. Benjamin Mast, and Dr. Paul Salmon, for their time and contribution.

Dr. Susan Folstein and Dr. Helen Tager-Flusberg, who taught me the value of conducting research and provided me with guidance in my work and studies. Families of the children with Williams syndrome, who devoted their time to participate in this project.

Members of Dr. Mervis's lab, for their help with data collection, and especially to Angie John, for being a great friend and making this experience more enjoyable. And finally, my family: my husband, Michael Leyfer, for his understanding and patience, and for being there for me every step of the way; my sister, Dr. Margarit Ordukhanyan, for setting an inspiring example of dedication to scholarship and the many words of wisdom offered in the process of writing my dissertation; and, most importantly, my mother, Ruzanna Harutyunyan, for giving me all the opportunities to succeed in life and for her endless support and encouragement of my educational endeavors. 


\section{ABSTRACT}

\section{ANXIETY DISORDERS IN CHILDREN WITH WILLIAMS SYNDROME, THEIR MOTHERS, AND THEIR SIBLINGS: IMPLICATIONS FOR THE ETIOLOGY OF ANXIETY DISORDERS}

\section{Ovsanna Leyfer}

October 16, 2006

Genetic factors play an important role in the etiology of anxiety disorders. Williams syndrome (WS), a genetic disorder caused by a deletion on chromosome $7 \mathrm{q} 11.23$ and associated with increased prevalence of anxiety disorders relative to the general population and other genetic disorders associated with intellectual disability, can be used in the search for susceptibility genes for anxiety disorders. This study examines the prevalence of anxiety disorders in children with WS, their mothers, and their siblings as well as predictors of anxiety in these groups, in order to facilitate the use of WS in studies of genetics of anxiety disorders.

Anxiety disorders were assessed in 109 children with WS ages 4 - 16 years, 106 mothers, and 72 siblings in the same age range. Prevalence was compared to that in the general population. Children with WS had a significantly higher prevalence of specific phobia, generalized anxiety disorder (GAD), and separation anxiety in comparison to children in the general population. The mothers had a significantly higher prevalence of GAD than women in the general population, but the prevalence rate for GAD in this group prior to the birth of the child with WS was comparable to that for women in the general population. The siblings had a significantly higher prevalence of specific phobia 
in comparison to children in the general population, but it was similar to the rates reported in other studies of specific phobia in typically developing children.

The odds of a child with WS having an anxiety disorder increased with age and the severity of maternal anxiety. The odds of mothers having an anxiety disorder increased if the mother was not employed outside of home and if the child with WS was a male.

The elevated prevalence rates of anxiety disorders in children with WS suggest a connection between the deletion found in WS and anxiety disorders. Given the increased prevalence of anxiety disorders in children with WS, genetic studies examining possible links between particular gene(s) deleted in WS and anxiety are warranted. It would also be worthwhile to investigate relations between genes deleted in WS and genes previously implicated in anxiety disorders. 


\section{TABLE OF CONTENTS}

PAGE

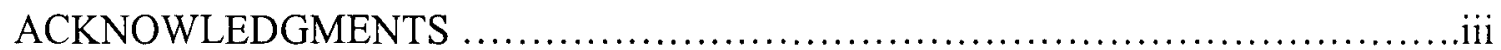

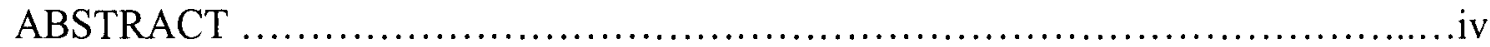

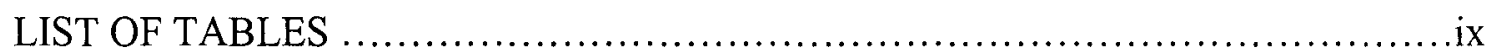

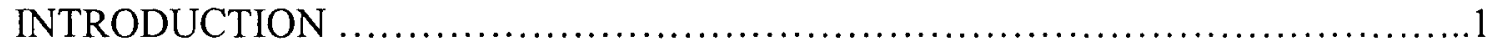

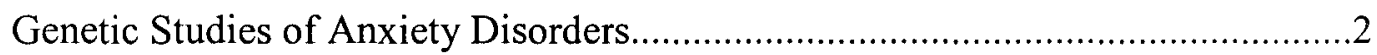

Family and twin studies of anxiety disorders..........................5

Linkage and association studies....................................11

Summary and potential problems of genetic studies of anxiety disorders. 16

Anxiety Disorders in Williams Syndrome................................19

Anxiety in Parents and Siblings of Children with Developmental Disabilities....26

Summary and Research Questions.......................................32

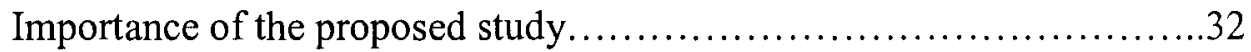

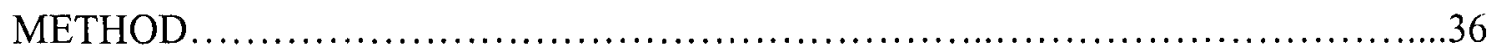

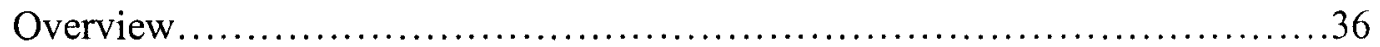

Number of Participants.....................................................

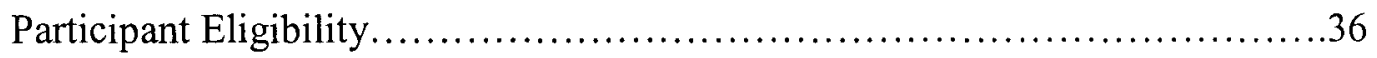

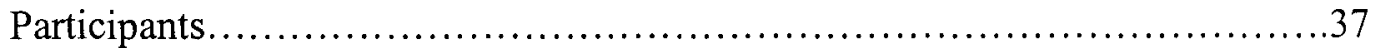

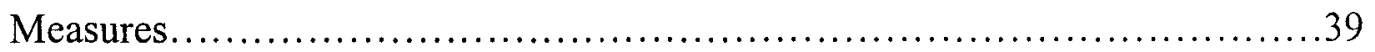

Anxiety Disorders Interview Schedule-IV ..........................40

Anxiety Disorders Interview Schedule, Parent version..................40 
Differential Ability Scales.

Scales of Independent Behavior-Revised............................42

Child Behavior Checklist.........................................43

Training/Reliability of Student Clinical Interviewers..........................44

Procedure................................................................ 44

Data Analyses.........................................................45

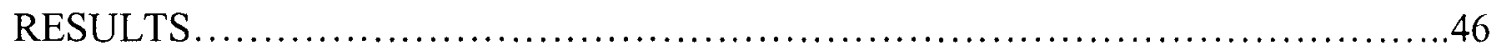

Tests of Specific Research Questions......................................46

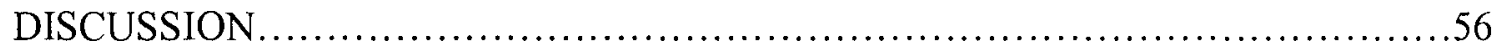

Children with WS.......................................................56

Prevalence of anxiety disorders in children with WS...................56

Predictors of anxiety in children with WS............................58

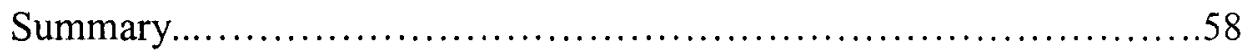

Mothers of Children with WS..............................................59

Prevalence of anxiety disorders in mothers of children with WS..........59

Predictors of anxiety in mothers of children with WS....................59

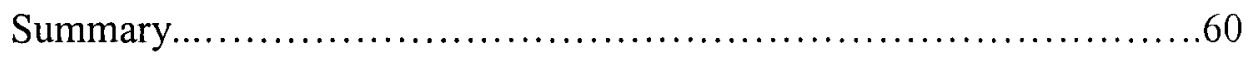

Siblings of Children with WS..........................................61

Prevalence of anxiety disorders in siblings of children with WS..........61

Predictors of anxiety in siblings of children with WS....................62

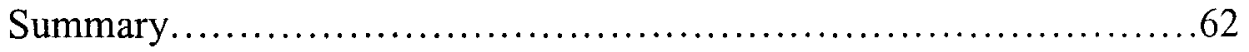

Implications for Genetic Research on Anxiety Disorders..............................62

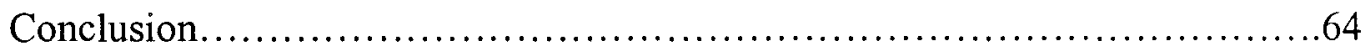


REFERENCES.

CURRICULUM VITAE. 


\section{LIST OF TABLES}

TABLE

PAGE

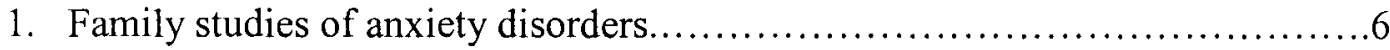

2. Twin studies of anxiety disorders........................................ 9

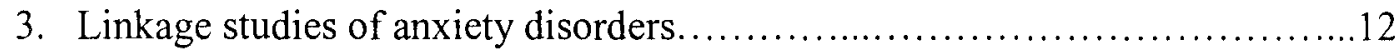

4. Association studies of anxiety disorders................................ 15

5. Anxiety disorders in first-degree relatives of children with autism and DS.....26

6. Prevalence of anxiety disorders in children with $\mathrm{WS}(\mathrm{N}=109)$ and the general population

7. Comparison of prevalence rates in children with WS with and without siblings in the $4-16$ year age range ............................................ 48

8. Prevalence of anxiety disorders in mothers of children with WS $(\mathrm{N}=106) \ldots \ldots .49$

9. Prevalence of anxiety disorders in children with WS and their siblings........51

10. Logistic regression analysis summary for predictors of severity of anxiety in children with WS

11. Logistic regression analysis summary for predictors of severity of anxiety in the

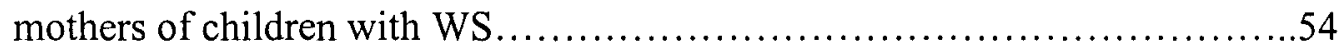

12. Correlation between severity of sibling anxiety and WS-related variables......55 


\section{INTRODUCTION}

Family and genetic studies of anxiety disorders have demonstrated that genetic factors play an important role in their etiology. Although a number of candidate chromosomal regions, genes, and polymorphisms have been linked to anxiety disorders (reviewed in Arnold, Zai, \& Richter, 2004), many of the initial findings are conflicting, and no specific genes have been identified thus far. In part this is due to the fact that even though anxiety disorders aggregate in families, their mode of inheritance does not follow a clear Mendelian pattern (i.e., dominant, recessive, or X-linked). These are complex disorders that appear to be caused by an interaction among a variety of genes as well as environmental factors (Smoller, Finn, \& White, 2000).

A number of chromosomal and genetic disorders caused by deletions, trisomies, or translocations are known to be associated with specific behavioral characteristics, referred to as behavioral phenotypes (Flint, 1998). These behavioral characteristics may include psychiatric features independent of the cognitive profiles of the disorders, but the complete profiles of the psychiatric features and their risk factors are unknown in these disorders. Examination of genetic neurodevelopmental disorders associated with high prevalence rates of a particular psychiatric disorder provides a complementary approach in the search for susceptibility genes for complex disorders. Karayiorgou and Gogos (1997) state that to reliably determine a causal relationship between a chromosomal abnormality and a disease, at least one or preferably both of the following criteria must be 
demonstrated: 1) increased frequency of the disease in a population with the chromosomal abnormality and 2) increased frequency of the chromosomal abnormality in the population with the disease. Studies of complex disorders such as schizophrenia and Alzheimer disorder (Murphy, 2002; Murphy \& Owen, 2001; Schupf \& Sergievsky, 2002) have demonstrated the success of this approach.

The same approach may be applied to attempt to locate susceptibility genes for anxiety disorders. In individuals with Williams syndrome (WS), a genetic disorder caused by a deletion on chromosome 7q11.23 (Ewart et al., 1993), anxiety disorders have been found at a significantly higher prevalence than in the general population and in other genetic disorders associated with intellectual disability (e.g., Leyfer, Woodruff-Borden, Klein-Tasman, Fricke, \& Mervis, 2006). However, the causes of anxiety in individuals with WS are unclear. Systematic studies of anxiety disorders in individuals with WS and their first-degree relatives will shed light on the possible relationship between the genes involved in anxiety disorders, family history of anxiety, and anxiety disorders in individuals with WS and open the door for further genetic studies of anxiety. The purpose of this dissertation is to provide the first such study. In the remainder of the introduction, I review three sets of literature that provide background for this project: genetic studies of anxiety disorders, anxiety disorders in WS, and anxiety in mothers and siblings of individuals with developmental disabilities (DD).

\section{Genetic Studies of Anxiety Disorders}

Anxiety disorders are among the most common psychiatric disorders, with a lifetime prevalence of approximately $25 \%$ in adults (Kessler et al., 1994) and $4-9 \%$ in children (Ford, Goodman, \& Meltzer, 2003; Shaffer et al., 1996). Moreover, many adult 
anxiety disorders have their onset in childhood or adolescence and have a chronic course (e.g., Burke, Burke, Regier, \& Rae, 1990; Kendall et al., 1993). They are also highly comorbid with each other and other psychiatric disorders, especially with mood disorders (e.g., Belzer \& Schneier, 2004) and are associated with high levels of occupational and social impairment (e.g., Kessler, Dupont, Berglund, \& Wittchen, 1999).

The Diagnostic and Statistical Manual of Psychiatric Disorders (DSM-IV-TR; APA, 2000) specifies seven main types of anxiety disorders in children and adults: separation anxiety, panic disorder (PD), specific phobia, social anxiety disorder (SAD), generalized anxiety disorder (GAD), obsessive-compulsive disorder (OCD), posttraumatic stress disorder (PTSD), and acute stress disorder. Separation anxiety, typically diagnosed in childhood and adolescence, affects $0.6-4.1 \%$ of children (Anderson, Williams, McGee, \& Silva, 1987; Benjamin, Costello, \& Warren, 1990; Ford et al., 2003; Verhulst, van der Ende, Ferdinand, \& Kasius, 1997). It is characterized by excessive anxiety associated with separation from home or caregivers.

$\mathrm{PD}$ is associated with panic attacks and persistent concern about the future recurrence of attacks as well as worry about the consequences of the panic. The prevalence of $\mathrm{PD}$ in the general population ranges from $1 \%$ to $3.5 \%$ (APA, 2000; Kessler et al., 1994). In females, the lifetime prevalence of PD is as high as 5\% (Kessler et al., 1994). In children it is very rare; Ford et al. (2003) found it in $0.1 \%$ of their sample. Specific phobia refers to the excessive fear of specific objects or situations, subsequent avoidance of those, and/or distress associated with exposure to these objects or situations (APA, 2000). The lifetime prevalence rates of specific phobia in children and adolescents range from $1 \%$ (Ford et al., 2003) to $17.6 \%$ (Muris \& Merckelbach, 2000), with 
somewhat higher prevalence in females than males. In adults, Kessler et al. (1997) report lifetime prevalence rates of $6.7 \%$ in males and $15.7 \%$ in females. SAD is the excessive fear of social and performance situations and subsequent avoidance of and/or distress associated with exposure to the situation (APA, 2000). Ford et al. (2003) report social phobia in $0.3 \%$ of children and adolescents. In adults, the prevalence rates range from $3 \%$ to $13 \%$ (APA, 2000). It is more common in females $(15.7 \%$; Kessler et al., 1994) than in males (11.1\%; Kessler et al., 1994). GAD is associated with excessive worry or anxiety across a number of situations and events, which is hard to control (APA, 2000). The anxiety is accompanied by a range of physiological symptoms, such as restlessness, sleep disturbance, muscle tension, and fatigue. Studies using DSM-III or DSM-III-R criteria have found the rate of GAD in children to range from $2 \%$ to $4 \%$ (Achenbach, Connors, Quay, Verhulst, \& Howell, 1989; Anderson et al., 1987; Bowen, Offord, \& Boyle, 1990; Shaffer et al., 1996). Using the DSM-IV criteria, the prevalence of GAD is $0.7 \%$ in children and adolescents (Ford et al., 2003). The decrease in prevalence is most likely due to the use of more restrictive criteria for GAD in DSM-IV relative to those in DSMIII and DSM-III-R. In a community sample of adults, the lifetime prevalence of GAD is $5.1 \%$ (Kessler et al., 1994). OCD is characterized by obsessions - persistent intrusive thoughts that may not make sense and/or compulsions - repetitive driven behaviors that the individual performs in response to obsession or in accordance with specific rules (APA, 2000). The prevalence of OCD has been reported to be $0.3 \%$ in an epidemiological study of children and adolescents (Ford et al., 2003) and 1.6\% (lifetime prevalence) in an epidemiological study of adults (Kessler et al., 2005). The prevalence rates are similar in males and females (Karno \& Golding, 1991; Karno, Golding, 
Sorenson, \& Burnam, 1988). PTSD is diagnosed in individuals who have been exposed to a traumatic event during which they experienced intense fear, helplessness, or inability to control the situations and who subsequently re-experience the event through intrusive recollections, dreams, or flashbacks. The prevalence reports in adults have varied from $1 \%$ to $9 \%$ (APA, 2000; Helzer, Robins, \& McEvoy, 1987; Kessler, Sonnega, Bromet, Hughes, \& Nelson, 1995). In females, it has been reported to be higher ( $8.9 \%)$ than males (1.9\%; Kessler et al., 1995). Ford et al. (2003) have reported a prevalence rate of $0.1 \%$ in children.

Given their high prevalence and the accompanying impairment, the etiology of anxiety disorders is of major interest and importance. It can be investigated through a number of genetic approaches. Family studies provide information about familial aggregation of a disorder (Woodman, 1993) and usually serve as the starting point for any psychiatric genetic study (Kendler, 1997). If the prevalence of the condition is higher in the relatives of the affected individuals (probands) than in those of unaffected individuals, a condition is considered to be familial. Twin studies provide information about heritability by means of comparing the concordance rate for a specific condition in pairs of monozygotic (MZ) and dizygotic (DZ) twins (Woodman, 1993). Finally, association and linkage studies seek to identify specific genes or chromosomal regions related to anxiety disorders.

Family and twin studies of anxiety disorders. Several family studies of anxiety disorders have been conducted. The majority of these studies have focused on PD and OCD. However, the familiality of GAD, specific phobia, and SAD has been investigated to some degree as well. The familiality of separation anxiety and PTSD has 
not been established. Familial aggregation of separation anxiety is difficult to examine because of its age-specific nature, and family studies of PTSD have not been feasible because of the role of environmental causes in its etiology (Smoller et al., 2000). The findings of family studies of are summarized in Table 1. These studies have used structured diagnostic or family history interviews to assess anxiety disorders in the firstdegree relatives of individuals with an anxiety disorder and a control group of individuals without any psychiatric disorder. Morbidity risk (MR) refers to the estimated risk in relatives for the same anxiety disorder as diagnosed in the proband (Hettema, Neale, \& Kendler, 2001).

\section{Table 1}

Family studies of anxiety disorders

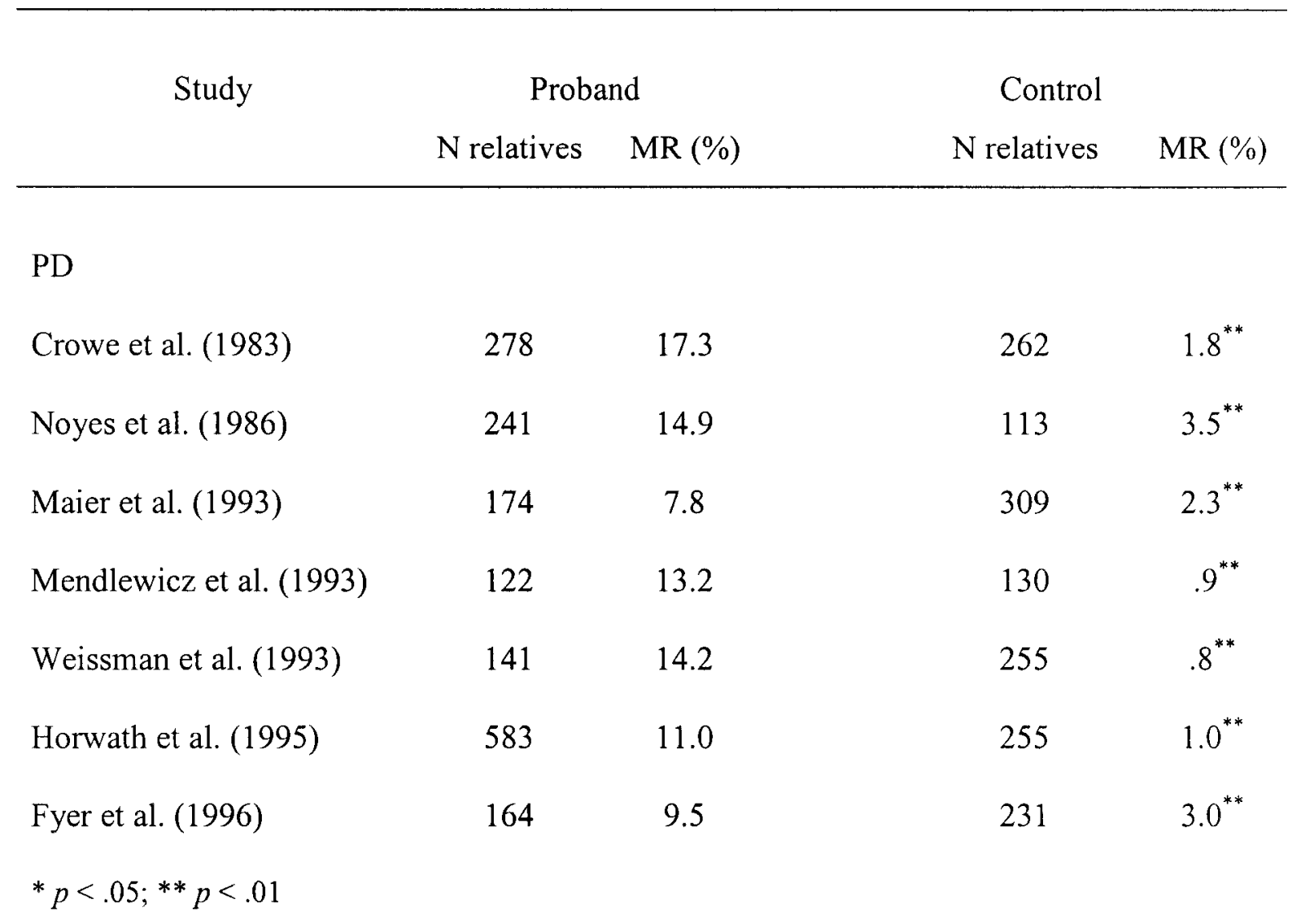




\section{Table 1 (cont.)}

Family studies of anxiety disorders

Study

Proband

Control

$\mathrm{N}$ relatives $\quad$ MR (\%)

$\mathrm{N}$ relatives $\quad$ MR $(\%)$

OCD

Black et al. (1992)

120

2.6

129

2.4

Pauls et al. (1995)

466

10.3

113

$1.9^{* *}$

Nestadt et al. (2000)

343

11.7

300

$2.7^{* *}$

Reddy et al. (2001)

122

4.9

128

$0^{* * 1}$

Hanna et al. (2005)

102

22.5

39

$2.6^{* *}$

GAD

Noyes et al. (1987)

278

17.3

262

$1.8^{* *}$

Mendlewicz et al. (1993)

241

14.9

113

$3.5^{* *}$

Specific phobia

174

7.8

309

$2.3^{* *}$

Fyer et al. (1990; 1995)

122

13.2

130

$.9^{* *}$

SAD

141

14.2

255

$.8^{* *}$

Fyer et al. (1996)

583

11.0

255

$1.0^{* *}$

Stein et al. (1998)

164

9.5

231

$3.0^{* *}$

${ }^{*} p<.05 ;{ }^{* *} p<.01$

'Lifetime prevalence rates were reported instead of MR

These studies clearly demonstrate familiality of specific anxiety disorders.

Familial aggregation of anxiety disorders in general has been demonstrated as well. For 
example, Merikangas and colleagues (Dierker, Merikangas, \& Szatmari, 1999; Merikangas, Avenevoli, Dierker, \& Grillon, 1999; Merikangas, Swendsen, Preisig, \& Chazan, 1998) examined the risk of developing an anxiety disorder in children ages 7-17 years of parents with either an anxiety disorder, substance abuse disorder, or no psychiatric diagnosis. Results indicated that the risk of developing an anxiety disorder in children was three times as high when they had one parent with an anxiety disorder than when they had a parent with a substance abuse disorder or without a psychiatric diagnosis. Turner, Beidel, and Costello (1987) found that children of parents with anxiety disorders were seven times more likely to develop an anxiety disorder than children of control parents without a psychiatric diagnosis.

Once familiality of the disorder has been established, twin and adoption studies can be conducted to differentiate genetic and environmental sources of familial aggregation of a disorder. As no adoption studies have been conducted on anxiety disorders to date (Hettema et al., 2001), twin studies are the only available means to control for environmental influences on familial aggregation. They establish heritability of a disorder by comparing the concordance rate for a specific condition in pairs of $\mathrm{MZ}$ and DZ twins (Woodman, 1993). MZ twins have identical genetic make-up, whereas DZ twins share on average $50 \%$ of their genes, yet both $\mathrm{MZ}$ and $\mathrm{DZ}$ twins are assumed to be subjected to the same environmental factors both pre- and post-natally. Table 2 summarizes the findings of twin studies of anxiety disorders. 


\section{Table 2}

Twin studies of anxiety disorders

\begin{tabular}{|c|c|c|c|c|}
\hline Study & $\mathrm{N}$ & Sex & \multicolumn{2}{|c|}{ Concordance $(\%)$} \\
\hline PD & & & $\mathrm{MZ}$ & $\mathrm{DZ}$ \\
\hline Torgersen (1983) & 598 & Male, female & 30.6 & 0 \\
\hline Kendler et al. (1993) & 2163 & Female & 20.7 & 14.5 \\
\hline Skre et al. (1993) & 49 & Male, female & 41.7 & 16.7 \\
\hline Perna et al. (1997) & 120 & Male, female & 73.0 & 0 \\
\hline Scherrer et al. (2000) & 6724 & Male & .47 & $.05^{1}$ \\
\hline GAD & & & $\mathrm{MZ}$ & $\mathrm{DZ}$ \\
\hline Andrews et al. (1990) & 924 & Male, female & 21.5 & 13.5 \\
\hline Skre et al. (1993) & 49 & Male, female & 60.0 & 14.3 \\
\hline Scherrer et al. (2000) & 6724 & Male & .39 & $.13^{1}$ \\
\hline Hettema et al. (2001) & 6200 & Male, female & 22.9 & 19.5 \\
\hline Specific phobia & & & $\mathrm{MZ}$ & $\mathrm{DZ}$ \\
\hline \multirow[t]{3}{*}{ Kendler et al. (1992) } & 2163 & Female & & \\
\hline & & Animal & 25.9 & 11.0 \\
\hline & & Situational & 22.2 & 23.7 \\
\hline
\end{tabular}


Table 2 (cont.)

Twin studies of anxiety disorders

$\begin{array}{llll}\text { Study } & \text { N } & \text { Sex } & \text { Concordance }(\%)\end{array}$

Specific phobia (cont.)

$\mathrm{MZ}$

$\mathrm{DZ}$

Neal et al. (1994)

$1858 \quad$ Female

Medical

.33

$.32^{1}$

Kendler et al. (2001) $2396 \quad$ Male

$\begin{array}{lll}\text { Animal } & 15.9 & 7.7 \\ \text { Situational } & 21.2 & 6.5\end{array}$

$\begin{array}{lll}\text { Medical } & 15.6 & 4.1\end{array}$

SAD

$\mathrm{MZ}$

$\mathrm{DZ}$

Kendler et al. (1992)

2163 Female

24.4

15.3

Kendler et al. (2001)

2396 Male

12.6

9.8

OCD

Carey \& Gottesman (1981) 30

Skre et al. (1993)

${ }^{\top}$ Tetrachoric correlations

${ }^{2}$ Obsessive symptoms only

The results of twin studies appear to be mixed, with concordance rates varying tremendously from one study to the next. This is partially due to the fact that the 
majority of studies have used community samples, which have a low number of affected twins. However, in all of these studies with the exception of Kendler et al.'s (1992) finding about specific phobia, situational type, the concordance rates are higher for MZ twins than for DZ twins. Hettema et al. (2001), in a meta-analysis of twin studies of anxiety disorders, estimate $30-40 \%$ heritability for anxiety disorders, depending on the disorder. Once the heritability of a disorder has been established, molecular genetic studies can be conducted to identify specific susceptibility genes.

Linkage and association studies. Until 15 years ago, genetics could only be researched abstractly, based on findings from twin studies (Kendler, 1997). However, the human genome project enabled geneticists to begin identifying genes implicated in Mendelian disorders (Kendler, 1997) and opened the door for genetic studies of complex psychiatric disorders. Currently two methods are used in molecular genetic research on complex disorders: linkage and association. Linkage studies involve genotyping DNA markers either in large families (pedigrees) or in pairs of related individuals with the disorder to determine the chromosomal region containing the susceptibility genes (Arnold, Zai, \& Richter, 2004). Association studies involve comparing allelic frequencies of a candidate gene in affected individuals to those in controls (van West \& Claes, 2004). Because linkage studies do not require prior knowledge of the pathophysiology of the disorder, they have served as the starting point in the search for genes for many complex conditions, including anxiety disorders. Table 3 reviews the results of several linkage studies of anxiety disorders. 


\section{Table 3}

Linkage studies of anxiety disorders

Study Disorder Sample characteristic Locus Sign. ${ }^{1}$

$\begin{array}{lll}\text { Camp et al. (2005) } & \text { Co-morbid } \quad 87 \text { extended pedigrees } & 18 \mathrm{q} 21.3 \quad \text { Yes } \\ & \text { major } & 3-\mathrm{q} 22.2 \\ & \text { depression and } & \\ & \text { any anxiety } \\ & \text { disorder }\end{array}$

Hanna et al. (2002) OCD 7 extended pedigrees $9 \mathrm{p} 24 \quad$ No

$\begin{array}{llll}\text { Crowe et al. (1987) PD } & \text { 26 extended pedigrees } & 16 \mathrm{q} 22 & \text { No }\end{array}$

Knowles et al. (1998) PD 23 extended pedigrees $1 p, 20 p$,

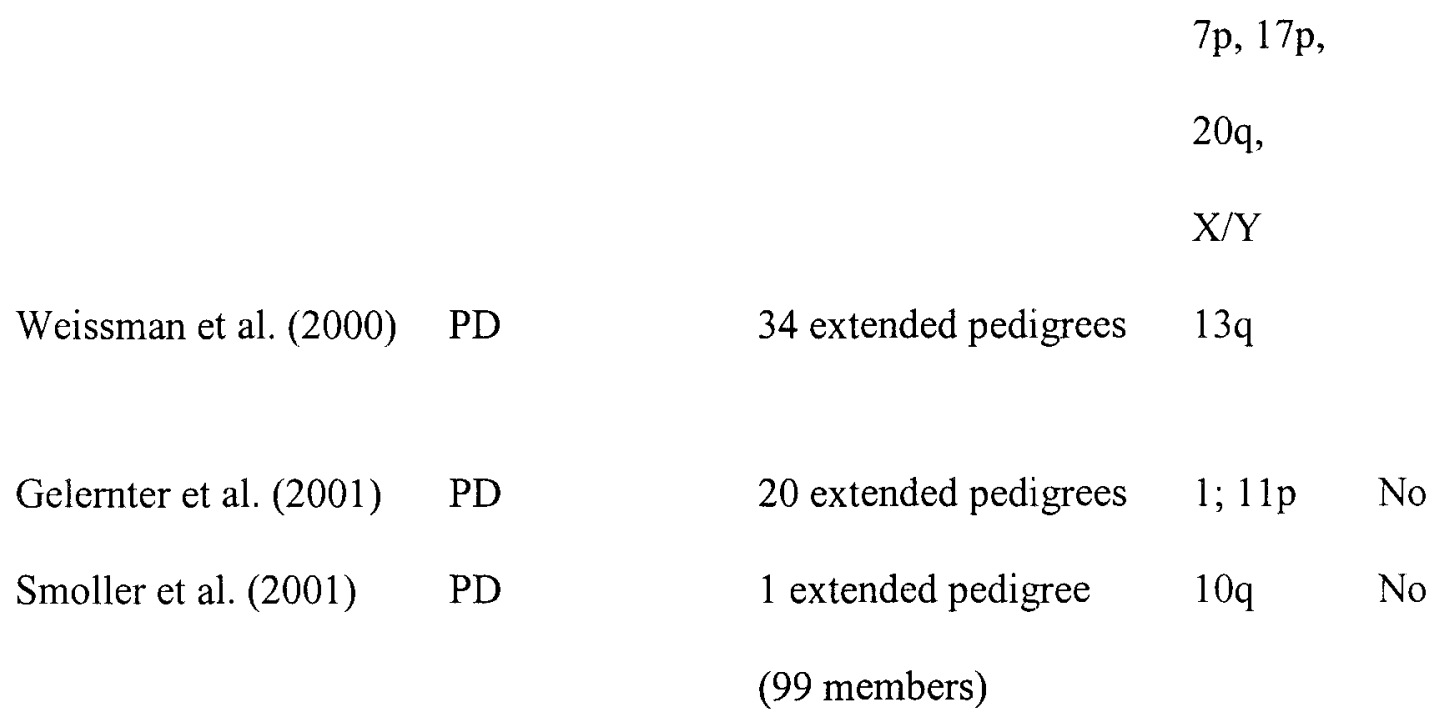

${ }^{1}$ Linkage is considered significant if the limit of detection (LOD) score, the statistic used for linkage analysis, is greater than 3.0 (Woodman, 1993). 
Table 3 (cont.)

Linkage studies of anxiety disorders

\begin{tabular}{lllll}
\hline \multicolumn{1}{c}{ Study } & Disorder & Sample characteristic & Locus & Sign. $^{\prime}$ \\
\hline Hamilton et al. (2003) & PD & 60 extended pedigrees & $13 \mathrm{q}$, & Yes \\
& & & $22 \mathrm{q}$ & \\
Thorgeirsson et al. & PD & 25 extended pedigrees & $9 \mathrm{q} 31$ & Yes \\
(2003) & & & & \\
Gelernter et al. (2004) & SAD & 14 extended pedigrees & $16 \mathrm{q}$ & No \\
Gelernter et al. (2003) & Specific phobia & 17 extended pedigrees & $14 \mathrm{p}$ & Yes \\
\hline
\end{tabular}

'Linkage is considered significant if the limit of detection (LOD) score, the statistic used for linkage analysis, is greater than 3.0 (Woodman, 1993).

Although linkage studies do not require a priori knowledge of the pathophysiology of the disorder in detecting the location of the genes associated with a disorder in families with multiple affected members, this method poses certain problems. First, linkage studies tend to have low power in detecting small effect sizes (Risch \& Merikangas, 1996); for a linkage study to have enough power to detect small effect sizes, one needs more than 100 pedigrees (Kendler, 1997). Yet the largest linkage study of an anxiety disorder has only included 87 pedigrees (Camp et al., 2005). Additionally, calculations of linkage are biased by the p11resence of individuals who have genetic risk factors for the disorder, but do not have the disorder itself (Van West \& Claes, 2004). As is apparent from Table 3, with the exception of the PD signal on 13q, none of the linkage findings has been replicated, and, even if they were, linkage studies only identify the 
chromosomal region in which the susceptibility genes are located; the genes themselves can only be identified by means of association studies.

Because the pathophysiology of anxiety disorders remains unclear, choosing candidate genes for association studies poses certain difficulties. Thus far, the association studies of anxiety disorders have been based on pharmacological and neurobiological studies, which have implicated several neurotransmitter systems in the pathophysiology of anxiety disorders (Arnold et al., 2004). Some of the most recent association studies of anxiety disorders are reviewed in Table 4 . Similar to the family studies, the majority of research to date has been done on PD and OCD.

The findings of association studies are conflicting thus far. This may be due to several design factors. First, the selection of the control group will affect the results tremendously, because the differences between the two groups may not be related to genetics (Bird, Jarvik, \& Wood, 2001). To minimize this problem, Arnold et al. (2004) suggest using family-based association methods similar to the one used by Kennedy et al. (2001). Other problems include possible frequency differences in disease alleles in different populations (Munafo \& Flint, 2004) and small effect sizes. To be conclusive, the association findings must be replicated in large family-based association studies of homogeneous subpopulations. 
Table 4

Association studies of anxiety disorders

Gene Study Disorder N N Assoc.

Serotonin receptor $(5 \mathrm{HT})$

$\begin{array}{lllll}\text { 5HT1A } & \text { Inada et al. (2003) } & \text { PD } & 63 & \text { No } \\ & \text { Rothe et al. (2004) } & \text { PD } & 134 & \text { Yes }^{\prime} \\ \text { 5HT2A } & \text { Stein et al. (1998) } & \text { SAD } & 17 \text { families } & \text { No } \\ & \text { Hemmings et al. (2003) } & \text { OCD } & 71 & \text { No } \\ & \text { Inada et al. (2003) } & \text { PD } & 63 & \text { Yes } \\ \text { 5HT1B } & \text { Camarena et al. (2004) } & \text { OCD } & 72 \text { families } & \text { Yes }{ }^{2} \\ & \text { Lochner et al. (2004) } & \text { OCD } & 178 & \text { Yes }^{2} \\ & \text { Hemmings et al. (2003) } & \text { OCD } & 71 & \text { No }^{2}\end{array}$

Catchol-O-methyltransferase (COMT)

$\begin{array}{lccc}\text { Alsobrook et al. (2002) } & \text { OCD } & 56 \text { families } & \text { Yes }^{3} \\ \text { Erdal et al. (2003) } & \text { OCD } & 59 & \text { No } \\ \text { Domschke et al. (2004) } & \text { PD } & 115 & \text { Yes }^{3}\end{array}$

Cholecystokinin (CCK)

A receptor

Ise et al. (2003)

PD

50

No

Miyasaka et al. (2004)

PD

109

Yes

\footnotetext{
'Only for PD with agoraphobia

${ }^{2}$ In males only

${ }^{3}$ In females only
} 


\section{Table 4 (cont.)}

Association studies of anxiety disorders

Gene Study Disorder N N Assoc.

Dopamine Receptor

$\begin{array}{lllll}\text { DRD2 } & \text { Kennedy et al. (2001) } & \text { SAD } & 17 \text { families } & \text { No } \\ \text { DRD2 } & \text { Lawford et al. (2003) } & \text { PTSD } & 63 & \text { Yes }^{1} \\ \text { DRD3 } & \text { Kennedy et al. (2001) } & \text { SAD } & 17 \text { families } & \text { No } \\ \text { DRD4 } & \text { Kennedy et al. (2001) } & \text { SAD } & 17 \text { families } & \text { No } \\ \text { DRD4 } & \text { Hemmings et al. (2003) } & \text { OCD } & 71 & \text { No }\end{array}$

Monoamine oxidase (MAOA)

$\begin{array}{lccc}\text { Hemmings et al. (2003) } & \text { OCD } & 71 & \text { No } \\ \text { Tadic et al. (2003) } & \text { GAD } & 196 & \text { Yes } \\ \text { Lochner et al. (2004) } & \text { OCD } & 178 & \text { Yes }\end{array}$

\footnotetext{
'Association with improved social functioning after treatment

Summary and potential problems of genetic studies of anxiety disorders. Family studies of anxiety disorders indicate than these disorders aggregate in families. Twin studies support this finding and further suggest that at least part of the familiality is accounted for by genetics. A number of linkage and association studies have been conducted, but their findings are inconclusive. Genetic studies of anxiety disorders are complicated for several reasons. First, although the family studies often demonstrate increased incidence of a particular anxiety disorder in first-degree relatives of probands with this disorder, the first-degree relatives of these probands also appear to be at
} 
increased risk for other anxiety disorders. For example, in the family study of OCD by Black et al. (1992; see Table 1), the morbidity risk for OCD was not significantly higher than in the relatives of the control group, but the morbidity risk in these relatives was significantly higher than in control relatives for any anxiety disorder $(p<.025)$.

Similarly, in twin studies when the anxiety disorders are combined into a single category, the concordance rates increase noticeably for both $\mathrm{MZ}$ and $\mathrm{DZ}$ twins (e.g., Andrews et al., 1990; Torgersen, 1983).

Second, anxiety disorders are highly co-morbid with each other and with affective disorders (e.g., Barlow, DiNardo, Vermilyea, Vermilyea, \& Blanchard, 1986). There is also a great deal of overlap in clinical features among the DSM anxiety disorders (Finn, Rutledge-Gorman, \& Crabbe, 2003). For example, panic disorder, social and specific phobias, and OCD are associated with harm avoidance. This overlap is also evident in genetic findings for both anxiety and depressive disorders. For example, association has been reported between MAOA and GAD as well as between MAOA and OCD (Lochner et al., 2004; Tadic et al., 2003). MAOA has also been implicated in genetic studies of depressive disorders (e.g., Gutierrez et al., 2004; Kunugi et al., 1999). This evidence combined with the high morbidity risk of anxiety disorders in the first degree relatives of individuals with a specific anxiety disorder suggests that the boundaries between the DSM-IV anxiety disorders (and possibly depressive disorders) are not very clear; hence using them for gene-mapping may not be very informative. Therefore, identification of susceptibility genes may require a further definition of the anxiety phenotype (Smoller \& Tsuang, 1998). 
Finally, the main difficulty in studying the genetics of anxiety disorders is the fact that, similar to other psychiatric disorders, they are complex, genetically heterogeneous disorders. Most likely their manifestations are related to multiple genes and their interaction with each other and the environment. Genome scans and association studies based on knowledge from pharmacological and neurobiological research have not been successful so far in identifying genes for anxiety. Therefore, at this point it may be useful to consider complementary strategies from examples of genetic studies of other complex disorders.

It is already known that individuals affected by developmental disorders of specific congenital cause may share typical behavioral features referred to as behavior phenotypes. Oftentimes psychiatric disorders may be a prominent part of these phenotypes. Murphy (2002) suggests that examining chromosomal abnormalities in which psychiatric disorders aggregate may be very successful for understanding the genetics of complex psychiatric disorders. Further, linkage and association studies can be conducted using the genetic markers on the locus or the genes implicated in the chromosomal abnormality. Also, hypotheses may be made about the interaction of the chromosomal region involved in the abnormality and genes that have already been implicated in these disorders (e.g., serotonin transporter for anxiety disorders). This strategy becomes particularly relevant in the case of anxiety disorders. It has been noticed that individuals with WS, a syndrome involving a known chromosomal abnormality, exhibit high levels of anxiety, resembling at least some of the DSM-IV anxiety disorders. Following the criteria suggested by Karayiorgou and Gogos (1997), if elevated prevalence of anxiety disorders in comparison to the general population can be 
established in individuals with WS, this syndrome may serve to search for genes implicated in anxiety disorders.

\section{Anxiety Disorders in Williams Syndrome}

WS is a neurodevelopmental disorder caused by a microdeletion of $\sim 25$ genes on chromosome 7q11.23 (Ewart et al., 1993; Osborne, 2006). It is associated with mild to moderate mental retardation or learning difficulties, a characteristic facies, heart disease (especially supravalvar aortic stenosis), hypercalcemia, and failure to thrive in infancy (Morris, 2005). The cognitive phenotype for WS includes relative strengths in verbal short-term memory and language and extreme weakness in visuospatial construction, including writing, drawing, and pattern construction (e.g., Mervis et al., 2000). A number of studies have considered the behavioral and emotional characteristics of individuals with WS (e.g., Dykens, 2003; Einfeld, Tonge, \& Florio, 1997; Einfeld, Tonge, \& Rees, 2001; Einfeld et al., 1999; Gosch \& Pankau, 1997; Klein-Tasman \& Mervis, 2003). A variety of problem behaviors (e.g., distractibility, restlessness) and personality characteristics (e.g., social disinhibition, excessive talking, mood swings, anxiety) have been identified.

The earliest study of behavioral problems in children with WS was conducted by Udwin, Yule, and Martin (1987). They compared the behaviors of 20 children with WS to those of 20 children with mental retardation (MR) due to other causes matched on chronological age (CA), sex, socioeconomic class, and verbal IQ, using the Rutter Parent and Teacher Scales. The children with WS were reported to have higher rates of anxiety, sleep disturbance, hyperactivity, and social isolation. Udwin and Yule (1991) later compared another sample of 20 children with WS to 20 matched children with MR; 
findings indicated that the children with WS exhibited higher scores on the Neurotic subscale (which would be indicative of anxiety) than the control group, but the difference was not statistically significant.

In a study of personality characteristics of children with WS, Klein-Tasman and Mervis (2003) found that one aspect of the distinctive personality of these children is their tendency toward anxiety. These researchers used the Children's Behavior Questionnaire (CBQ; Rothbart \& Ahadi, 1994) and Multidimensional Personality Questionnaire - Parent Version (MPQ; Tellegen, 1985) to compare personality characteristics of children with WS age $8-10$ years to those of a comparison group of children with developmental disabilities (DD) of mixed etiologies matched for CA and IQ. The children with WS were significantly less shy, more gregarious, less dominant, more empathic, more sensitive, and more tense than the comparison group.

Einfeld and colleagues (Einfeld et al., 1997; Einfeld et al., 1999; Einfeld et al., 2001; Tonge \& Einfeld, 2003) examined behavioral characteristics of children with WS using the Developmental Behavior Checklist (DBC; Einfeld \& Tonge, 1995), a parentreport instrument specifically designed to assess behavioral and emotional disturbances in individuals who have MR. This group assessed 70 children with WS (mean CA: 9.4 years). Comparisons were made to an epidemiologically-derived control group; gender, CA and level of MR were statistically controlled. The WS group had a significantly higher Total Behavior Problems score. Subscale analyses indicated that the WS group had significantly more problems on the Communication Disturbance and Anxiety subscales. A significantly higher proportion of the parents of the children in the WS group endorsed the following items: tense or anxious, overaffectionate, covers ears or 
avoids particular sounds, overactive, short attention, food fads, obsessed/preoccupied with an idea or activity, overly attention seeking, doesn't mix with own age group/prefers adult company, inappropriately happy or elated, wanders aimlessly, and repeats words or phrases. Based on these findings, Einfeld and his colleagues concluded that WS may have a distinct behavioral phenotype.

Results of two longitudinal comparisons have also been reported. Einfeld et al. $(1999,2001)$ presented a 5 -year follow-up (Time 2). Although the Total Behavior Problems score for the WS group decreased, the difference was not significant. There was a significant decrease for the WS group for one item (repeats words or phrases). Differences between the WS group and the epidemiological control group remained significant for the Total Behavior Problems score, the Anxiety and Communication Disturbance subscales, and for all but two of the items listed above (overactive, and obsessed /preoccupied with an idea or activity). An 8-year follow up (Time 3; Tonge \& Einfeld, 2003) indicated that the Total Behavior Problems score for the WS group decreased significantly in comparison to Time 1 (no comparisons to Time 2 were reported), although it was still significantly higher than for the epidemiological control group. Scores on 3 of the 5 subscales (Disruptive/Antisocial, Self-absorbed, and Anxiety) decreased significantly. The WS group scored significantly higher than the epidemiological control group on the Communication Disturbance subscale; scores for the two groups did not differ significantly for the other 4 subscales. These findings suggested that behavioral problems in individuals with WS persist over time, although they may become less severe with age. 
Switaj (2000) examined anxiety-related behaviors and traits in children with WS and how their manifestations may change over time. The 1500 members of the Williams Syndrome Association who had children ages 6 - 18 years were invited to participate in a mail survey study. Parents of 190 children (12.6\%) completed the surveys. The following measures were included: Child Behavior Checklist (CBCL; Achenbach, 1991), Behavior Assessment System for Children (BASC; Reynolds \& Kamphaus, 1992), the Revised Children's Manifest Anxiety Scale (RCMAS; Reynolds \& Richmond, 1985) and the Yale-Brown Obsessive-Compulsive Symptom Checklist (Y-BOCS; Goodman, Price, Rasmussen, Riddle, \& Rapoport, 1986). The results were compared across the following age groups: $6-9,10-13$, and $14-18$ years. The $14-18$ year age group received significantly higher scores on the Anxious/Depressed subscale of the CBCL than did the two younger groups. On the RCMAS, the scores for the three age groups were significantly different. The youngest group received the lowest scores, the 10-13 year age group received significantly higher scores than the 6-9 year age group, and the 14-18 year age group received significantly higher scores than the 10-13 year age group. On the BASC, the 10-13 year age group received significantly higher scores than the 6-9 year age group. No age differences were apparent in the YBOCS scores.

These studies point to a high level of behavior problems in individuals with WS, particularly preoccupations, fear, and anxiety. However, their reports are based on questionnaires and behavior rating scales that compare children with WS to a contrast group. This type of assessment presents several problems. Although the measures used in the above-cited studies provide quantifiable information regarding the presence and severity of behaviors, they typically do not solicit information about many variables that 
are essential for the diagnosis of psychiatric disorders, such as the impairment associated with the symptoms, the duration of the symptoms, and the context in which the behavior takes place (see Dykens, 2000). Finally, it is possible that similar-sounding subscales on different instruments measure different behaviors, depending on the items included in them.

The use of rating scales and checklists does not allow for conclusions about prevalence rates of DSM-IV diagnoses of anxiety disorders. Yet, it is essential to obtain diagnostic information in order to fulfill at least one of the requirements for establishing a causal relationship between a known chromosomal abnormality and a disease, which is the increased frequency of the disease in the population with the chromosomal abnormality (Karayiorgou \& Gogos, 1997). The information about DSM-IV diagnoses of anxiety disorders can be obtained by means of structured and semi-structured interviews, which are usually based on a diagnostic system such as the DSM or ICD. However, very few studies of the behavioral phenotype in WS have used diagnostic interviews.

The first study to use a DSM-based interview to address psychopathology in WS was conducted by Dykens (2003). Dykens examined rates of anxiety disorders in individuals with WS using the anxiety domain of the Diagnostic Interview Schedule for Children-Parent Version (DICA-R), a semistructured interview based on DSM-III-R (APA, 1987) criteria. The interview was administered to caregivers of 51 individuals with WS ranging in age from 5 to 49 years. The interview demonstrated $35 \%$ prevalence for specific phobia, $16 \%$ prevalence for overanxious disorder (GAD), and $4 \%$ and $2 \%$ prevalence for separation anxiety and OCD respectively. However, the study had several 
shortcomings. First, it used an interview based on DSM-III-R criteria, a limitation that is particularly relevant to the diagnosis of GAD, the criteria for which are much stricter in DSM-IV. Second, both children and adults were included, even though anxiety disorders may not be the same from childhood to adulthood.

Cherniske et al. (2004) examined psychiatric characteristics in 20 adults with WS ages 30-52 years. Information was collected from the participants directly and/or their parents by means of various diagnostic interviews, including the Anxiety Disorders Interview Schedule (ADIS; Brown, DiNardo, \& Barlow, 1994), the Schedule for Affective Disorders and Schizophrenia (SADS; Spitzer \& Endicott, 1978) administered to the participants, and an adaptation of the Kiddie-SADS (Ambrosini, 2000) administered to their caregivers. Thirteen participants were diagnosed with an anxiety disorder, the most common one being a specific phobia ( $50 \%$ of the sample) and the second most common one being GAD (prevalence rate not reported). One person ( $5 \%$ of the sample) was diagnosed with OCD and another one was diagnosed with panic disorder. Although the sample in the study was very small and a variety of different interviews and information sources were used, the pattern of the results was similar to the findings of Dykens (2003), who reported that specific phobia was the most prevalent anxiety disorder, followed by GAD. Nevertheless, the prevalence of specific phobia in this sample was considerably higher than the one reported by Dykens (2003).

Leyfer et al. (2006) examined the prevalence of psychiatric disorders in children with WS, using the Anxiety Disorders Interview Schedule, Parent version (ADIS-P; Silverman \& Albano, 1996), a structured interview based on DSM-IV (APA, 1994) criteria. The interview was administered to the caregivers of 119 children with WS, ages 
4-16 years. The results demonstrated $53.8 \%$ prevalence of specific phobia, similar to the previous findings by Cherniske et al. (2004). GAD was found in $11.8 \%$. Almost $7 \%$ of the group had separation anxiety, and $2.5 \%$ had OCD. SAD was diagnosed in $1.7 \%$ of the children. PTSD and PD were found in $0.8 \%$ of the group each. The prevalence rates were then compared across the following age groups: 4-6 years, 7-10 years, and 11-16 years. The prevalence of specific phobia and separation anxiety did not differ as a function of CA. The youngest group had a significantly lower rate of GAD $(0 \%)$ than expected in contrast to the oldest group (22.9\%).

In summary, although only a few studies have investigated the psychiatric profile of individuals with WS, the preliminary evidence suggests that WS meets the first criterion suggested by Karayiorgou and Gogos (1997) and hence WS may be used to search for genes implicated in anxiety disorders. However, several steps must be undertaken to facilitate this research. First, data on anxiety disorders in WS using large samples and reliable and valid instruments based on DSM-IV criteria must be collected systematically. The next step is investigation of familial aggregation of anxiety disorders in the first degree relatives of individuals with WS, such as their parents and siblings, to examine the relationship between family history of anxiety and anxiety in WS.

Comparison of the children with WS to their siblings will allow to some degree the separation of familial effects (whether environmental or genetic) from the effects of the WS deletion. Depending on patterns of familial aggregation of anxiety disorders, various hypotheses may be made about the relationship of the genes deleted in individuals with WS and anxiety disorders. Finally, because the interaction of genes and environment has been implicated in the etiology of anxiety disorders, it is important to 
examine whether environmental factors are implicated in anxiety in individuals with WS and their families. To date, no studies have examined the prevalence of anxiety disorders in family members of individuals with WS. However, a number of studies of psychopathology in family members of children with other forms of DD have been conducted.

Anxiety in Parents and Siblings of Children with Developmental Disabilities

The most extensive research on the prevalence of anxiety disorders in parents of individuals with DD has been conducted on parents of individuals with autism in comparison to parents of individuals with Down syndrome (DS), a genetic disorder caused by an extra copy of chromosome 21 (trisomy 21). These studies have used the Schedule for Affective Disorders and Schizophrenia, Lifetime version (SADS-L; Spitzer \& Endicott, 1978; Table 5).

Table 5

Anxiety disorders in parents of children with autism and DS

Autism DS

Piven et al. (1991)

$\mathrm{N}=81$

$\%$

$\mathrm{N}=34$

$\%$

Anxiety disorders (total)

19

23.5

1

$2.9^{*}$

GAD

10

12.3

1

2.9

PD

3

3.7

0

Phobic disorder

8

9.9

0 


\section{Table 5 (cont.)}

Anxiety disorders in parents of children with autism and DS

Autism

DS

\begin{tabular}{lcccc}
\hline OCD & 0 & & 0 \\
Piven \& Palmer (1991) & $\mathrm{N}=48$ & $\%$ & $\mathrm{~N}=30$ & $\%$ \\
GAD & 2 & 4.2 & 1 & 3.3 \\
SAD & 7 & 14.6 & 1 & $3.3^{*}$ \\
Specific phobia & 2 & 4.2 & 1 & 3.3 \\
OCD & 1 & 2.1 & 0 & 0 \\
\hline$p<.05$ & & &
\end{tabular}

Results of these two studies indicated higher incidence of anxiety disorders in parents of children with autism than in parents of children with DS. However, with the exception of GAD in the first study, the rates of anxiety disorders for parents of children with autism are consistent with those for the general population (Kessler et al., 1994).

Anxiety in parents of children with DS has been studied using self-report questionnaires. For example, Spangenberg and Theron (2001) assessed anxiety in 60 parents of children with DS using the State-Trait Anxiety Inventory (STAI; Spielberger, 1983), reporting anxiety in $48 \%$ of the sample. However, because the STAI scores were not reported, it is impossible to compare these findings to those in the general population.

Lenhard, Breitenbach, Ebert, Schindelhauer-Deutscher, and Henn (2005) administered the STAI to parents of 411 mothers of children with DS, 66 mothers of children with MR of unknown origin, and 69 mothers of TD children. There was no difference in STAI scores between mothers of children with DS and mothers of TD 
children. In contrast, mothers of children with MR of unknown origin scored significantly higher on the STAI than the other two groups, which according to the authors, may have been due to the uncertainty the mothers had about their children's diagnoses. The diagnostic uncertainly in turn may lead to inadequate services and lack of social support. It is also possible that parents of children with DS in general have lower rates of anxiety in comparison to parents of children with other types of DD.

Harvey, O'Callaghan, and Vines (1997) compared anxiety levels as measured by the Delusions-Symptoms-States Inventory of Anxiety and Depression (Bedford \& Foulds, 1978) in a group of 65 mothers of children with DD of mixed etiology and a group of 75 mothers of TD children. Out of 7 symptoms included in the anxiety subscale of the instrument, significantly more mothers of children with developmental delays endorsed feelings of panic and restlessness. No significant difference was found in the frequency of the remaining 5 symptoms.

It is unclear whether parents of children with DD have elevated anxiety in comparison to the general population. However, it is possible that anxiety levels among parents of children with DD may vary depending on the child's behaviors, level of functioning and other such variables. For example, Baker, Blacher, Crnic, and Edelbrock (2002) examined parenting stress in parents of 92 3-year-old children with MR of mixed etiology (excluding autism) and 133 TD 3-year-old children. Child behavior was assessed

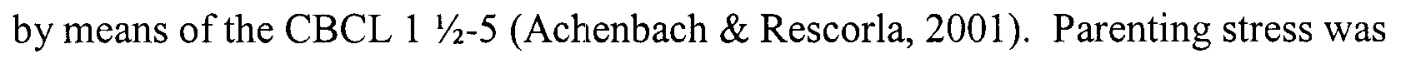
assessed by means of the Family Impact Questionnaire (Donenberg \& Baker, 1993), which measures the child's impact on the family. In comparison to parents of children without $\mathrm{DD}$, parents of children with $\mathrm{DD}$ reported significantly higher parenting stress, 
which may in turn lead to anxiety. A regression analysis demonstrated that the majority of the stress was predicted by the child's behavior.

In an attempt to investigate this issue further, Weiss, Sullivan, and Diamond (2003) examined adaptive functioning of children with DD and how this variable may relate to parental stress. Participants consisted of 90 mothers and 56 fathers of individuals with DD of various etiologies. The ages of the individuals with DD ranged from 9.3 to 42.5 years, with an average age of 24.9 years. The Adaptive Behavior Scales - Residential and Community Edition (Nihira, Leland \& Lambert, 1993) was used to assess their adaptive behavior. Parenting stress was measured by means of The Parenting Stress Index (Abidin, 1995). The results demonstrated that lower adaptive functioning scores predict higher levels of parental stress.

Emerson (2003a) investigated variables associated with negative psychological outcomes for 245 mothers of children with DD in comparison to 9,481 mothers of children with TD. Results demonstrated that socio-economic status was associated with worse psychological outcomes for mothers in general. Mothers of children with DD tended to report lower rates of mental health problems in comparison to mothers of children with TD. However, mothers of children with DD reported a higher psychological impact of their child's difficulties than did the mothers of children with TD. A regression analysis demonstrated that the following factors related to having a child with DD contributed to the prevalence of mental health problems in the mothers: if the child with DD is a male, poverty, and the parent's perception of the social impact of the child's difficulties. 
Fidler, Hodapp, and Dykens (2000) examined what child variables may affect the levels of stress in families of 20 children with WS and compared them to two other groups (families of children with DS or Smith-Magenis syndrome). For the parents of the children with WS, the strongest predictors of family stress were younger age of the child and maladaptive behavior as measured by the CBCL total problems T score (Achenbach, 1991); these variables together accounted for $59 \%$ of the variance in family stress. For parents of children with DS or Smith-Magenis syndrome, the only significant predictors were younger age and the CBCL total problems T score respectively, each accounting for $32 \%$ of the variance in family stress. In summary, it is possible that some child variables may be predictive of anxiety in parents of children with WS. These variables may include adaptive functioning and types of behavioral problems exhibited by the children. Also demographic factors such as family income, child age, child gender, and marital status may predict anxiety in parents of children with WS.

Studies of behavior problems of siblings of children with other forms of DD have yielded contradictory findings. Fisman et al. (1996) compared internalizing and externalizing behaviors of siblings of children with DD and siblings of TD children using the Survey Diagnostic Instrument (Cadman, Boyle, \& Offord, 1988), a behavior checklist adapted from the CBCL (Achenbach \& Edelbrock, 1983). No significant difference was found between siblings of children with DD and the control siblings in either internalizing or externalizing behaviors.

Dyson (1999) compared 37 siblings of children with DD (including MR of unknown etiology and learning disorders) and 34 children who did not have a sibling with DD. Child behaviors were rated by parents using the CBCL (Achenbach, 1991). No 
difference was found on the Internalizing and Externalizing scales of the CBCL between siblings of children with DD and the control group.

Only two studies have investigated anxiety in siblings of children with DD. Neither of these studies included diagnostic interviews, hence the prevalence of anxiety disorders in this population is unknown. McHale and Gamble (1989) investigated anxiety in 31 children with a sibling with MR (etiology unspecified) and 31 children without a sibling with MR, using the RCMAS (Reynolds \& Richmond, 1985). These authors reported a significantly higher anxiety score for siblings of children with MR than for the controls.

Coleby (1995) used the RCMAS to investigate anxiety in siblings of children with severe DD. The sample consisted of 41 children ages 5-16 years who had siblings with severe or profound MR (etiology unspecified) and 41 children in the same age range with TD siblings. Anxiety was measured by the RCMAS (Reynolds \& Richmond, 1985). No difference was found in the RCMAS scores between the two groups of siblings.

In summary, very few studies have investigated anxiety in parents and siblings of children with DD. Currently there is no conclusive evidence on the prevalence of anxiety disorders in the $1^{\text {st }}$ degree relatives of individuals with DD. Most studies on parents have been conducted with parents of individuals with autism or DS. The findings of these studies are contradictory. Some evidence is available that child behaviors and level of adaptive functioning may affect psychological outcomes for parents. No such variables have been studied for siblings of children with DD. 


\section{Summary and Research Questions}

Family and twin studies have demonstrated that anxiety disorders aggregate in families. Moreover, the concordance rates of anxiety disorders are higher for MZ twins than for DZ twins, suggesting that the familial aggregation is at least in part determined by genetics. With the exception of 13q, none of the genetic linkage findings on anxiety disorders has been replicated. Association studies of anxiety disorders have found significant associations between some anxiety disorders and several genes, including MAOA, COMT, and DRD4. However, thus far these findings have been conflicting. Most likely several genes and their interactions with each other and the environment are involved in the etiology of anxiety disorders.

WS, a congenital disorder caused by a deletion of $\sim 25$ genes on chromosome $7 q 11.23$ and associated with elevated prevalence rates of anxiety disorders, appears to be a good candidate for examining the genes involved in anxiety. In order to examine the relationship between the genes deleted in WS and anxiety, it is important to first examine the prevalence of anxiety disorders in individuals with WS, their siblings, and their parents. The primary objective of this dissertation project was to gather these data for the following family members: the child with WS, the child's mother, and the sibling (if any) closest in age to the child with WS. In addition, the roles of several potential predictors of anxiety in the probands, their mothers, and their siblings were examined.

Importance of the proposed study. To date, no family studies of anxiety disorders have been conducted for individuals with WS. Depending on the findings, these data may have varying implications for the study of the genetics of anxiety disorders. Because there are three groups involved in the study (probands, mothers, and TD 
siblings) and a possibility of each one of these groups having an incidence of anxiety disorders either higher than or similar to (or lower than) the general population, 8 outcomes are plausible. This study focuses on the following questions to address these possibilities.

(1). Do children with WS have higher prevalence rates of anxiety disorders than children in the general population?

Leyfer et al. (2004) have demonstrated that children with WS have a much higher prevalence of specific phobia than do children with TD. Also, older children with WS have a significantly higher prevalence of GAD than TD children of the same CA. However, no comparisons of anxiety prevalence rates have been made to epidemiological samples of children with TD. In order to establish whether WS can be utilized to study the genetics of anxiety disorders, this comparison is imperative.

(2). Do mothers of children with WS have a lifetime prevalence of anxiety disorders similar to that for women in the general population?

Research on anxiety in parents of children with various forms of DD demonstrates that parental anxiety may vary as a function of type of child DD. No data are available for mothers of children with WS. The present study aimed to establish the prevalence of anxiety disorders in mothers of children with WS and compare it to the known prevalence rates of anxiety disorders in women in the general population.

(3). Do siblings of children with WS have a lifetime prevalence of anxiety disorders similar to that for children in the general population? Do children with WS have a higher prevalence of anxiety disorders than their siblings? 
No data are available on the prevalence of anxiety disorders in siblings of children with DD in general. Findings using questionnaires and checklists are contradictory. The present study examined the prevalence of anxiety disorders in siblings of children with WS and compared it to the known prevalence rates of anxiety disorders in children in the general population. It also compared these rates to the rates found in the siblings with WS.

(4). Is maternal anxiety correlated with anxiety in children with WS? Is maternal anxiety correlated with anxiety in siblings of children with WS? Is the relationship with maternal anxiety stronger for one of the child groups than for the other?

Researchers have demonstrated that there is a familial link of anxiety between parent and child (e.g., Merikangas et al., 1998). As described earlier in the Introduction, familial and twin studies of anxiety disorders have demonstrated that the heritability of anxiety disorders ranges from .30 to .40 . Based on this evidence, it was expected that presence of a lifetime diagnosis of an anxiety disorder in a mother will be significantly correlated with presence of an anxiety disorder both in a child with WS and in a TD sibling. Depending on the role of the deleted genes, this correlation may have been higher, lower, or the same for the probands than their TD siblings.

\section{(5). What factors influence anxiety in children with WS?}

As reviewed earlier in the Introduction, research on the etiology of anxiety disorders has demonstrated that genetics plays an important part in their transmission. However, as is the case with most forms of psychopathology, genetics does not fully account for their manifestation. Environmental factors may also contribute to the manifestations of anxiety disorders. To better understand the causes of anxiety disorders 
in children with WS, it is necessary to examine variables that may affect their presence in this population, including the child's level of adaptive functioning, CA, and gender as well as SES.

\section{(6). What factors influence anxiety in mothers of children with WS?}

More specifically, this question sought to examine how having a child with WS may impact maternal anxiety. Because both environmental and genetic causes have been implicated in the etiology of anxiety disorders (e.g., Fyer et al., 1990), both must be explored when examining the prevalence of anxiety disorders in mothers. Evidence from studies of parents of children with DD suggests that the child's behaviors, adaptive functioning, and gender as well as SES may impact psychological outcomes for parents. Variables related to the child with WS that are likely to impact the parental level of anxiety, such as level of adaptive functioning, gender, and behavioral problems, as well as maternal employment status, were examined as possible predictors of maternal anxiety.

\section{(7). What factors influence anxiety in siblings of children with WS?}

This question sought to examine what factors may influence anxiety in TD siblings of children with WS. No studies on siblings of children with DD have focused on such variables. 


\section{METHOD}

\section{Overview}

The proposed study investigated the prevalence of anxiety disorders in children with WS (probands), mothers of children with WS, and their TD siblings as well as possible predictors of anxiety in the probands, their mothers, and their TD siblings. The presence of anxiety disorders was assessed by means of a structured diagnostic interview. The intellectual and adaptive functioning of the children with WS were assessed by means of standardized instruments.

\section{Number of Participants}

Based on the suggestion by Cohen (1992), a power analysis was conducted to determine the number of participants required for the study. To detect a medium effect size with a two-sided test with alpha at .05 and power of .80 , the number of participants required for a chi square test is 88 . To detect a medium effect size with alpha at .05 and power of .80 , a sample size of 55 is needed for a regression analysis with 1 predictor, a sample size of 68 is needed for a regression analysis with 2 predictors, 77 for 3 predictors, and 85 for 4 predictors.

\section{Participant Eligibility}

Participants eligible for the study included mothers who had biological children with WS between the ages of $4-16$ years whose WS diagnosis had been confirmed by a 
fluorescence in situ hybridization (FISH) test. The majority of the families also had another child in the same age range (half-siblings were included if they had the same mother). For three of the children with WS, maternal data were not available, but they were included in the study because they had a biological sibling eligible for participation in the study. Exclusionary criteria for the participants were: 1) the presence of another genetic or developmental disorder in the child with WS, 2) the presence of organic brain damage in the child with WS, and 3) the presence of a developmental disorder or organic brain damage in the mother or the sibling of the child with WS.

\section{Participants}

The participants were recruited through a study of language and cognitive development in children with WS conducted by Drs. Carolyn Mervis and Colleen Morris at the University of Louisville and the University of Nevada School of Medicine. The University of Louisville site primarily focuses on cognitive and language development, while the University of Nevada site focuses on genetic and medical aspects of WS. As part of a common protocol across the two sites, children completed the Differential Ability Scales (DAS; Eliot, 1990 a, b), and their mothers completed the Scales of Independent Behavior-Revised (SIB-R; Bruininks, Woodcock, Weatherman, \& Hill, 1996), the Anxiety Disorders Interview Schedule, Parent version (ADIS-P; Silverman \& Albano, 1996), and Anxiety Disorders Interview Schedule-IV (ADIS-IV; Brown, DiNardo, \& Barlow, 1994). All mothers of children with WS ages $4-16$ years who participated in the larger study were also invited to participate in the present study, and all agreed to participate. 
One hundred and twenty-four families of children with genetically-confirmed WS participated in this study. These children were consecutive participants within the 4-16 year age range in the Morris-Mervis study. Eleven families were excluded because the child with WS met the diagnostic criteria for autism or pervasive developmental disorder, not otherwise specificed based on clinical judgment following evaluation using the Autism Diagnostic Interview-Revised (Lord, Rutter, \& Le Couteur, 1994) and the Autism Diagnostic Observation Schedule (ADOS-G; Lord et al., 2000). One family was excluded from the study because the child with WS had a shorter deletion (fewer genes deleted than is typical for WS). Another family was excluded because the child with WS had a longer deletion (more genes deleted than is typical for WS); this child also met autism criteria as described above. Two families were excluded because the child with WS had organic brain damage. One family was excluded because the sibling had a diagnosis of pervasive developmental disorder, not otherwise specified.

For the remaining 109 children with WS (51 boys and 58 girls), mean chronological age $(\mathrm{CA})$ was 8.6 years $(\mathrm{SD}=3.1$ years, range $=4.0-16.9$ years $)$. Mean General Conceptual Ability Score (GCA; similar to IQ) on the Differential Ability Scales (DAS; Elliott 1990a, b) was $59.8(\mathrm{SD}=13.2$, range $=<25-94)$. Based on GCA, 20.2\% of the children had intellectual abilities in the normal range, $59.6 \%$ had mild mental retardation, $14.7 \%$ had moderate mental retardation, and $5.5 \%$ had severe mental retardation. WS is associated with a specific cognitive profile involving relative strength in verbal short-term memory and language and extreme weakness in visuospatial construction (Mervis et al., 2000). As such, GCA often provides an underestimate of the 
verbal abilities of children with WS (Meyer-Lindenberg, Mervis, \& Berman, 2006). All of the children, including those with severe mental retardation, were verbal.

One hundred and six mothers participated in the study. Mean CA for these mothers was 38.7 years $(\mathrm{SD}=5.7$, range $=25.9-58.2)$. Ninety-two $(86.8 \%)$ mothers were married, three $(2.8 \%)$ were single, and $11(10.4 \%)$ were divorced. Fifty-one mothers (48.1\%) reported not being employed outside of home; 55 mothers $(51.9 \%)$ reported being employed. Twelve per cent of the families reported a household income of $\$ 30,000$ or below, $21.3 \%$ reported a household income ranging from $\$ 31,000$ to 60,000 , and the remainder of the families reported a household income of above $\$ 60,000$. There was no significant difference in the reported household income between the mothers who were employed outside of home and the mothers who were not, $\chi^{2}(2)=0.64, p=.727$.

Ninety children with WS had at least one sibling; for 72, at least one sibling was between the ages of 4 and 16 years. The sibling in this age range who was closest in age to the child with WS participated in the study. The TD sibling group included 43 boys and 29 girls with a mean $\mathrm{CA}$ of 9.7 years $(\mathrm{SD}=3.3$ years, range $=4.2-16.5$ years). The mean $\mathrm{CA}$ for the children with WS who had siblings was 9.3 years $(\mathrm{SD}=3.1$, range $=4.0$ - 16.9); 34 were boys, and 38 were girls. There was no significant difference in age between the children with WS and the siblings, $t(70)=-0.81, p=.419$. There was no significant difference between the children with WS and the TD siblings in gender distribution, $\chi^{2}(1)=0.67, p=.476$.

\section{Measures}

Data collected for the present study included diagnostic interviews of mothers of children with WS to establish the presence or absence of an anxiety diagnosis in the 
mother and diagnostic interviews of mothers regarding their child with WS and the TD sibling closest in age to establish the presence or absence of an anxiety diagnosis in the children. All children with WS were administered a measure of general intellectual functioning. Information about the adaptive functioning of all children with WS was collected by means of a structured parent interview. Demographic information was collected as a part of the structured diagnostic interview.

Anxiety Disorders Interview Schedule-IV (ADIS-IV; Brown et al., 1994). Maternal diagnostic status was obtained with the ADIS-IV, a structured diagnostic interview based on DSM-IV (APA, 1994) criteria. The ADIS-IV allows for differential diagnosis of DSM-IV anxiety and related disorders in adults. The ADIS-IV provides information both about specific anxiety disorder diagnoses and their severity [rated on a scale from 0 (indicative of no anxiety) to 8 (indicative of very severe anxiety)].

Although no psychometric data are available for the ADIS-IV, the ADIS-IV: Lifetime Version (ADIS-IV-L) has been reported to have good to excellent reliability (kappas .58-.81; Brown, Di Nardo, Lehman, \& Campbell, 2001). Adequate test-retest reliability has also been reported for the predecessor of the ADIS-IV, the ADIS-Revised (Di Nardo, Moras, Barlow, Rapee, \& Brown, 1993), with kappas of .43 to .82 .

Anxiety Disorders Interview Schedule, Parent version (ADIS-P; Silverman \& Albano, 1996). The ADIS-P is a structured interview designed to diagnose anxiety disorders in children and adolescents (through age 16 years). It is based on DSM-IV criteria and is used both to determine the diagnosis and its severity. The ADIS-P allows for differential diagnoses among all the DSM-IV anxiety and related disorders and provides data regarding symptomatology, etiology, and the course of the disorder 
(Silverman, 1994). In addition to the information about the presence or absence of diagnoses, the ADIS-P provides information about their severity [rated on a scale from 0 (indicative of no anxiety) to 8 (indicative of very severe anxiety)].

Silverman, Saavedra, and Pina (2001) have found excellent reliability for SAD, social phobia, specific phobia, and GAD as well as excellent test-retest reliability for the interview. Usually the ADIS-P is administered together with the Child Schedule. However, the Child Schedule was not administered in the present study, because individuals with DD often are not be able to provide accurate reports of experiences (Sovner, 1986). Additionally, there is evidence suggesting that parents may be able to provide more reliable information about children's psychological and emotional states and behaviors than the children themselves (Edelbrock, Costello, Dulcan, Conover, \& Kalas, 1986; Edelbrock, Costello, Dulcan, Kalas, \& Conover, 1985).

The applicability of DSM-IV criteria to populations with DD has been widely discussed in the literature. Cooper, Melville, and Einfeld (2003) and Reiss, Levitan, and Szyszko (1982) argue that reported prevalence rates of psychopathology may be an underestimate in populations with DD. Sovner and Hurley (Sovner, 1986; Sovner \& Hurley, 1983, 1982a, 1982b) suggested that although they may be less likely to be diagnosed, adults with DD have psychiatric disturbances that are conceptually the same as DSM disorders. Brown, Aman, and Lecavalier (2004) argued that DSM-IV criteria are applicable to children and adolescents with mild or moderate MR. A small proportion $(5.5 \%)$ of the sample in this study fell in the severe range of intellectual disability, suggesting that the results may be a slight underestimate of the actual rates of anxiety disorders. 
Differential Ability Scales (DAS; Elliott $1990 a, b$ ). The DAS provides an assessment of general intellectual functioning. This measure was designed to provide specific information about an individual's strengths and weaknesses across a wide range of intellectual activities. The General Conceptual Ability (GCA; similar to IQ) is based on performance on the core subtests and has a mean of 100 and a standard deviation of 15.

There are two levels of the DAS: Preschool and School Age. Following the test author's recommendation for children who are expected to have below average intelligence, the Preschool Level was administered to all children who were 6 years 11 months or younger. The School Age Level was administered to the remaining children unless they were very low functioning; these children completed the Preschool Level. If necessary, the GCA was calculated using the extended norms, which are available for the Preschool Level through age 13 years 11 months and for the School Age Level through age 17 years 11 months.

Scales of Independent Behavior-Revised (SIB-R; Bruininks et al., 1996). The SIB$\mathrm{R}$ provides an assessment of adaptive behavior. The parent interview form of the instrument was administered. It consists of 259 items; each item is scored on a 4-point Likert scale. The items are divided into four clusters: Motor Skills (with Gross and Fine subscales), Social Interaction and Communication (with Social Interaction, Language Comprehension, and Language Expression subscales), Personal Living Skills (with Eating and Meal Preparation, Toileting, Dressing, Personal Self-Care, and Domestic Skills subscales), and Community Living Skills (with Time and Punctuality, Money and Value, Work Skills, and Home/Community Orientation subscales). Additionally, the SIB- 
$\mathrm{R}$ assesses three domains of maladaptive behavior: Internalized, Asocial, and Externalized. The Broad Independence standard score is based on parental responses to items in the Motor Skills, Social Interaction and Communication Skills, Personal Living Skills, and Community Living Skills clusters. This standard score has a mean of 100 and a standard deviation of 15 . The norms for the SIB-R extend from age 3 months to 90 years.

Child Behavior Checklist (CBCL; Achenbach \& Rescorla,, 2001a,b). The CBCL is a Likert scale that provides an assessment of behavioral problems of children from parents and/or other caregivers. Two versions of this instrument exist: one for children ages $1 \frac{1}{2}-5$ years and another for ages $6-18$ years. The $6-18$ year version consists of 120 items pertaining to emotional and behavioral problems and 20 competency items. The items yield the following subscales: Aggressive Behavior, Anxious/Depressed, Attention Problems, Delinquent Rule-Breaking Behavior, Social Problems, Somatic Complaints, Thought Problems, Withdrawn, Externalizing, Internalizing, and Total Problems. The $11 / 2-5$ year version consists of 99 items describing behavioral and emotional problems. These items yield the following subscales: Emotional Reactivity, Anxious/Depressed, Somatic Complaints, Withdrawn, Sleep Problems, Attention Problems, Aggressive Behavior, Anxiety, Pervasive Developmental Disorder, ADHD Total, Oppositional, Externalizing, Internalizing, and Total Problems. A score of 65 is considered the clinical cut-off on the scales for both versions. The Total Problems T score from both versions was used as a measure of behavioral problems in this study. 
All interviewers who administered the ADIS-IV and ADIS-P had successfully completed reliability training for the interview. Training for the ADIS consisted of the following components: reviewing the interview, observing videotaped or live administrations of the interview, and assigning diagnoses and severity ratings for each interview. Interviewers were required to obtain three consecutive matches on diagnosis and its severity. Upon completion of this process, the interviewer administered a practice ADIS. This interview was videotaped and was rated by a licensed clinical psychologist. If the interviewer and the clinical psychologist diagnoses matched on principal and additional diagnoses, the interviewer was permitted to administer the ADIS for the study. If the clinician disagreed with the student diagnoses, the student was required to administer another practice ADIS. All interview protocols were reviewed with a licensed clinical psychologist. Disagreements were resolved by discussion.

\section{Procedure}

At the beginning of the session, the rationale for the study was explained to the mothers (and fathers, if present) or legal guardians, any questions they had were answered, and then they were given an informed consent form and a HIPAA form to read and sign. Children ages 12 years or older were asked to sign assent forms, in the presence of their parent(s) or legal guardians, after the study had been explained to them and they had agreed to participate. After the consent, HIPAA, and assent (if appropriate) forms were signed, a licensed clinical psychologist, a doctoral level clinical psychology student, or a board-certified developmental behavioral pediatrician or clinical geneticist administered the ADIS-IV and the ADIS-P. The mother was administered the ADIS-P 
about the child with WS. If she had another child in the age range of 4-16 years, she was also administered an ADIS-P about that child. For families with more than one TD child in the $4-16$ year age range, the ADIS-P was administered about the sibling closest in age to the child with WS. During this time, the child with WS was administered the DAS by a member of Dr. Mervis's laboratory. During the same visit, the parents were also administered the SIB-R and the CBCL. For many of the participants in the longitudinal component of the study of language and cognitive development, more than one ADIS was available. In this case, the most recent ADIS was used for the analyses in this study.

\section{Data Analyses}

The majority of the analyses were performed using the entire dataset, which included both dyads (mothers and children with WS) and triads (mothers, children with WS, and a TD sibling in the same age range). Some of the analyses were conducted on the subset consisting of the triads only, and some were on dyads composed of children with WS and their TD siblings. Data analyses were performed using SPSS version 13. 


\section{RESULTS}

\section{Tests of Specific Research Questions}

(1) Do children with WS have higher prevalence rates of anxiety disorders than children in general population?

Prevalence rates for each type of anxiety disorder in children with WS were calculated (Table 6). Overall, $56.9 \%$ of all the children received a diagnosis of at least one anxiety disorder. The prevalence rate of anxiety disorders for the children with severe MR alone $(\mathrm{N}=6)$ was $50.0 \%$ and was similar to that found in the children with intellectual functioning in the average to moderate deficit range $(\mathrm{N}=103 ; 57.3 \%)$. The most prevalent anxiety disorder in the WS group was specific phobia, found in $50.5 \%$ of the children.

These prevalence rates were compared to those in the general population of children using a $z$-test, with the significance level set at .05 . For this comparison, the findings of the Child and Adolescent Mental Disorders Study (Shaffer et al., 1996), the largest epidemiological study of psychiatric disorders in children in the USA using a reliable and valid structured diagnostic interview (Diagnostic Interview Schedule for Children Version 2.3; Shaffer et al., 1996), were used (Table 6). The children with WS had a significantly higher prevalence of specific phobia, GAD, and separation anxiety than reported in the general population. 


\section{Table 6}

Prevalence of anxiety disorders in children with WS $(\mathrm{N}=109)$ and the general population

\begin{tabular}{|c|c|c|c|c|}
\hline & $\mathrm{N}$ & $\%$ & Population Prevalence (\%) & $z$ \\
\hline Separation anxiety & 7 & 6.4 & 2.3 & $2.9^{* *}$ \\
\hline SAD & 2 & 1.8 & 4.5 & -1.3 \\
\hline GAD & 8 & 7.3 & 3.1 & $2.6^{*}$ \\
\hline OCD & 1 & .9 & $-{ }^{1}$ & -- \\
\hline Specific phobia & 55 & 50.5 & 1.3 & $44.1^{* *}$ \\
\hline PTSD & 1 & .9 & $--^{1}$ & - \\
\hline \multicolumn{5}{|l|}{${ }^{*} p<.01 ; * * p<.001$} \\
\hline \multicolumn{5}{|c|}{${ }^{1}$ Prevalence not reported. } \\
\hline \multicolumn{5}{|c|}{ The prevalence rates of types of anxiety disorders were also compared between } \\
\hline \multicolumn{5}{|c|}{ children with WS who had a sibling in the same age range and those who did not. No } \\
\hline \multicolumn{5}{|c|}{ significant difference was found in the prevalence of anxiety disorders in general and of } \\
\hline \multicolumn{5}{|c|}{ specific anxiety disorders between WS children with and without siblings in the $4-16$} \\
\hline
\end{tabular}




\section{Table 7}

Comparison of prevalence rates in children with WS with and without siblings in the 4 16 year age range

Probands with siblings Probands w/out siblings

\begin{tabular}{lccccc} 
& $\mathrm{N}$ & $\%$ & $\mathrm{~N}$ & $\%$ & $\chi^{2}$ \\
\hline Any anxiety disorder & 22 & 55.6 & 40 & 59.5 & 0.2 \\
Separation anxiety & 4 & 10.8 & 3 & 6.4 & $\ldots$ \\
SAD & 0 & & 2 & 2.8 & $\ldots$ \\
GAD & 1 & 2.7 & 7 & 9.7 & $\ldots$ \\
OCD & 1 & 2.7 & 0 & & 1 \\
Specific phobia & 21 & 56.8 & 34 & 47.2 & 0.9 \\
PTSD & 1 & 2.7 & 0 & & \\
\end{tabular}

'Fisher exact test was calculated instead of chi square.

(2) Do mothers of children with WS have a lifetime prevalence of anxiety disorders similar to that of women in the general population?

Lifetime prevalence of each type of anxiety disorder was calculated for the mothers participating in the study (Table 8 ). Overall, $43.4 \%$ of the sample received a lifetime diagnosis of at least one anxiety disorder. The prevalence for each anxiety disorder and for anxiety disorders in general were then compared to the prevalence in the general population of women in the same age range, using a $z$ test, with a significance level of $p<.05$. For population prevalence, the findings of the National Comorbidity Study were used (Kessler et al., 1994, 1995, 2005; Table 8), adjusted to include the age 
range of the participants in this study. The prevalence of GAD in the mothers of children with WS was significantly higher than in the general population of women.

\section{Table 8}

Prevalence of anxiety disorders in mothers of children with WS $(\mathrm{N}=106)$

\begin{tabular}{lcccc}
\hline & $\mathrm{N}$ & $\%$ & $\begin{array}{c}\text { Population } \\
\text { prevalence }(\%)\end{array}$ & \\
& & & & \\
\hline PD & 4 & 3.8 & 5.0 & -0.6 \\
SAD & 15 & 14.2 & 15.7 & -0.4 \\
GAD & 24 & 22.6 & 7.2 & $6.1 *$ \\
OCD & 2 & 1.9 & 1.6 & 0.2 \\
Specific phobia & 17 & 16.0 & 15.7 & 0.1 \\
PTSD & 5 & 4.7 & 8.9 & -1.5 \\
$* p<.001$ & & & &
\end{tabular}

To control for the influence of having a child with $\mathrm{DD}$, the prevalence rates of anxiety disorders were also calculated excluding mothers who did not have an anxiety disorder prior to having a child with WS but reported the onset of an anxiety disorder after having a child with WS and described the onset as related to raising the child and/or learning about the child's diagnosis. Five mothers described the onset of their GAD symptoms as related to their children's diagnosis (three of these mothers also reported another anxiety disorder, such as SAD or specific phobia with an onset prior to the birth of their child with WS). Even after excluding the five mothers who described the onset of their GAD symptoms as related to their children's diagnosis from the analysis, the mothers of children with WS continued to have a significantly higher prevalence of GAD 
$(17.9 \%, z=4.26, p<.001)$ than was found in the general population of women. It is possible that the retrospective description of the circumstances precipitating the onset of GAD is not accurate, because these circumstances may in turn be affected by having a child with WS. For this reason, this study then examined the prevalence of GAD in the mothers prior to the birth of their child with WS, taking into consideration the date of onset of GAD as reported by the mothers. In this case, it was similar to that for the general population $(6.4 \% ; \mathrm{z}=-0.03, p=1)$.

(3) Do siblings of children with WS have a prevalence of anxiety disorders similar to that of children in the general population? Do children with WS have a higher prevalence of anxiety disorders than their siblings?

Prevalence rates of each type of anxiety disorder in siblings of children with WS $(\mathrm{N}=72)$ were calculated (Table 9). Overall, $20.8 \%$ of the siblings had a diagnosis of at least one anxiety disorder. The prevalence of each anxiety disorder and of any anxiety disorder was then compared to the prevalence in the general population of children with typical development, using a $z$ test, with a significance level of $p<.05$. For population prevalence, the findings of the Child and Adolescent Mental Disorders Study (Shaffer et al., 1996; Table 6) were used. The siblings of children with WS had a significantly higher prevalence of specific phobia $(p<.001)$ than children in the general population. The prevalence rates of anxiety disorders overall in children with WS were then compared to the prevalence in their TD siblings, using the McNemar test, a statistic used to test matched-pair data (Sheskin, 2000), with a significance level of $p<.05$. To control for environmental and genetic influences, only the subset of children with WS who had a sibling participating in the study $(\mathrm{N}=72)$ was used for this analysis. (As indicated in 
Table 7, no difference was found in the prevalence of anxiety disorders between children with WS with and without siblings.) The children with WS had a significantly higher prevalence of anxiety disorders overall than their siblings $(p<.001)$. Comparisons for categories of anxiety disorders were possible only for specific phobia. The children with WS had a significantly higher prevalence of specific phobia than their siblings $(p<.001)$. Comparisons for the remaining categories of anxiety disorders were not performed because of the low expected frequencies for some of the cells. Note, however, that the prevalence of GAD for the children with WS was more than double that of their siblings and that the prevalence of SAD for the children with WS was less than half that of their siblings.

\section{Table 9}

Prevalence of anxiety disorders in children with WS and their siblings

$$
\begin{aligned}
& \mathrm{TD}(\mathrm{N}=72) \quad \mathrm{WS}(\mathrm{N}=72) \\
& \begin{array}{llll}
\mathrm{N} & \% & \mathrm{~N} & \%
\end{array}
\end{aligned}
$$

\begin{tabular}{lcccc} 
Any anxiety d/o & 15 & 20.8 & 40 & $55.6^{*}$ \\
Specific phobia & 9 & 12.5 & 34 & $47.2^{*}$ \\
GAD & 3 & 4.2 & 7 & 9.7 \\
Separation anxiety & 2 & 2.8 & 3 & 4.2 \\
OCD & 0 & 0 & 2 & 2.8 \\
SAD & 5 & 6.9 & 2 & 2.8 \\
\hline$* p<001$ & & & &
\end{tabular}


(4) Is maternal anxiety correlated with anxiety in children with WS? Is maternal anxiety correlated with anxiety in siblings of children with WS? Is the relation with maternal anxiety stronger for one of the child groups than for the other?

Mothers were coded as "anxious" if they had had any anxiety disorder in their lifetime (43.4\% of the group) or "non-anxious" if there was no history of anxiety disorders. Children with WS and their siblings were coded as "anxious" or "nonanxious" based on the same criteria; $58.5 \%$ of the children with WS and $21.7 \%$ of the siblings were coded as "anxious." Three children with WS and their siblings were excluded from these analyses because no data were available for their mothers.

Tetrachoric correlations were used to examine the correlations between maternal and proband anxiety as well as between maternal and sibling anxiety. The correlation between maternal anxiety and anxiety in the child with WS was significant $(r=.46, p<$ $.001)$. The correlation between maternal and sibling anxiety was not significant $(r=.11$, $p=.368$ ). The correlation coefficients were then compared, using the Fisher $z$ transformation (Meng, Rosenthal, \& Rubin, 1992). The results of the $z$-test indicated that the correlation between maternal and proband anxiety was significantly higher than the correlation between maternal and sibling anxiety, $z=2.5, p=.014$.

(5) What factors influence anxiety in children with WS?

A logistic regression was conducted to determine the factors related to the presence of anxiety disorders in children with WS. For this question, data from the entire sample of children with WS were used, excluding those whose mothers did not participate in the study $(\mathrm{N}=106)$. The child's DAS GCA score, the age of the child with WS, the sex of the child with WS, and severity of maternal anxiety $(M=1.6, S D=2.2)$ 
were entered as covariates. The overall regression equation was significant, $\chi^{2}(4)=29.0$, $p<.001$. The model accounted for $33.4 \%$ of the variance in the anxiety in WS. The odds ratios are presented in Table 10, demonstrating that the odds of a child with WS having an anxiety disorder increase with the child's age and the severity of maternal anxiety.

\section{Table 10}

Logistic regression analysis summary for predictors of severity of anxiety in children with WS

$B \quad$ SE $\quad$ Odds ratio

\begin{tabular}{lccc} 
Age & .16 & .08 & $1.18^{*}$ \\
Sex & -.32 & .49 & .72 \\
DAS GCA & -.03 & .02 & .98 \\
Severity of maternal anxiety & .55 & .16 & $1.72^{* *}$ \\
\hline${ }^{*} p<.05 ;{ }^{* *} p<.01$ & & &
\end{tabular}

(6) What factors influence anxiety in mothers of children with WS?

A logistic regression analysis was conducted to determine the extent to which the adaptive functioning and sex of the child with WS as well as the mother's employment status predicted the presence of maternal anxiety. For this analysis, the mothers who reported the onset of their anxiety as occurring before having a child with WS were excluded $(\mathrm{N}=8)$. The SIB-R Broad Independence standard score for the child with WS $(\mathrm{M}=61.2, \mathrm{SD}=16.9)$, the Total Problem $\mathrm{T}$ score from the $\mathrm{CBCL}(\mathrm{M}=61.2 ; \mathrm{SD}=8.2)$, the sex of the child with WS, and the mother's employment status were entered as predictors. The overall regression equation was significant, $\chi^{2}(4)=14.4, p=.006$, the 
model accounting for $20.7 \%$ of the variance of the presence of anxiety in mothers. The odds ratios are presented in Table 11, indicating that the odds of having an anxiety disorder for a mother of a child with WS increase if the child is a boy and if the mother is not employed outside of the home.

\section{Table 11}

Logistic regression analysis summary for predictors of severity of anxiety in the mothers of children with WS

Model $\quad B \quad$ SE $\quad$ Odds ratio

\begin{tabular}{lccc} 
Sex & 1.03 & .51 & $2.79 *$ \\
SIB-R Broad Independence & -.03 & .02 & .98 \\
CBCL Total Problems & .02 & .03 & 1.02 \\
Maternal employment & -1.22 & .52 & $.30^{*}$ \\
\hline${ }^{*} p<.05$ & & &
\end{tabular}

(7) What factors influence anxiety in siblings of children with WS?

A logistic regression was conducted to test whether the same variables that were hypothesized to contribute to anxiety in children with WS also affected anxiety in their siblings. However, IQ was not included because no IQ data were collected for the siblings. Severity of maternal anxiety, sibling age, and sibling sex were entered as predictors. The overall regression equation was not significant, $\chi^{2}(3)=4.1, p=.248$, the model predicting only $9 \%$ of the variance. Because this model was not significant, Spearman's rho was computed to investigate whether sibling anxiety correlated with the 
DAS and SIB-R scores of the child with WS, their age, and severity of their anxiety

(Table 12). None of these correlations was significant.

\section{Table 12}

Correlation between severity of sibling anxiety and WS-related variables.

Variables

Rho

DAS GCA

SIB-R Broad Independence

CBCL Total Problems

Age of the child with WS

Severity of anxiety in the child with WS
$-.15$

.03

.14

$-.07$

.16 


\section{DISCUSSION}

The present study investigated the prevalence of anxiety disorders in children with WS, their mothers, and their siblings, using a DSM-IV-based structured diagnostic interview with good psychometric properties. In addition, this study investigated potential predictors of anxiety in children with WS, their mothers, and their siblings. The results are discussed in the order of groups in the study: children with WS, their mothers, and their siblings. The final section focuses on the implications of these findings for the genetics of anxiety disorders.

\section{Children with WS}

Prevalence of anxiety disorders in children with WS. The results of the study demonstrate that children with WS have elevated rates of anxiety disorders in comparison to children in the general population. These rates are also higher than those previously reported for TD children of mothers with an anxiety disorder $(20.6 \%$; Dierker et al., 1999). When examined by type, children with WS have a significantly higher prevalence of specific phobia, GAD, and separation anxiety than children in the general population.

In this study, the children with WS also had a significantly higher prevalence of anxiety disorders in general and of specific phobia than their siblings. No comparisons were made for other anxiety disorders because of the low frequency in both groups, but children with WS had higher rates of all anxiety disorders than their siblings except for social phobia. These findings are consistent with those of Klein-Tasman and Mervis 
(2003), who found that children with WS were significantly less shy and more gregarious, but more tense in comparison to the CA- and IQ-matched children with DD of mixed etiology.

These rates are also much higher than those previously reported for individuals with DD of other etiologies. For example, Myers and Pueschel (1991) reported phobias in only $1.5 \%$ of their sample of children and adolescents with Down syndrome. Antshel et al. (2006) reported specific phobia in $22.6 \%$ of their sample of children with Velocardiofacial syndrome (deletion 22q11 syndrome), separation anxiety in $4.8 \%$, and GAD in $16.7 \%$. The difference between their rates and the rates found in this study was most likely due to the age difference in the two studies; the mean age of the participants with deletion $22 \mathrm{q} 11$ in their study (11.7 years of age) was higher than the mean age of the children with WS in this study (8.9 years of age). Although the prevalence of GAD in Antshel et al.'s study is higher than found in WS in this study, it is similar to that reported by Leyfer et al. (2006) for 7-10-year old children with WS (13.6\%) and lower than reported by Leyfer et al. for 11-16-year-olds with WS (22.9\%). In children with Fragile $\mathrm{X}$ syndrome, Backes et al. (2003) reported separation anxiety in 10\% and OCD in $2 \%$. No other anxiety disorders were reported. In a study of prevalence of psychiatric disorders in 264 children with DD of mixed etiology, Emerson (2003b) reported 1.9\% prevalence of specific phobia and $2.7 \%$ prevalence of separation anxiety. Dekker and Koot (2003) reported $6.8 \%$ prevalence of specific phobia, $1.9 \%$ of separation anxiety, $1.5 \%$ of $\mathrm{OCD}$, and $0 \%$ of $\mathrm{GAD}$, resulting in $10.5 \%$ prevalence of anxiety disorders overall, in 474 7-20-year-olds with DD of mixed etiology. 
Predictors of anxiety in children with WS. The model that predicted the presence of anxiety in children with WS included the child's age, sex, IQ, and severity of maternal anxiety. Older children were more likely to have an anxiety disorder than younger children. The effect of age was expected based on the findings of Leyfer et al. (2006) showing older children with WS had a higher prevalence of GAD than younger children. It was also consistent with the findings of Switaj (2000) using anxiety rating scales and checklists, which showed that older children with WS have higher anxiety scores than younger children.

The increase in severity of maternal anxiety also increased the odds of a child with WS having an anxiety disorder. The relationship between maternal and child anxiety was also supported by the significant positive correlation between the presence of anxiety disorders in children with WS and their mothers.

Summary. These findings overall demonstrate an elevated rate of anxiety disorders in children with WS, which per Karayiorgou and Gogos (1997) is one of the two criteria demonstrating a causal relationship between a chromosomal abnormality and a disease, in this case $7 \mathrm{q} 11.23$ deletion and anxiety. The presence of maternal anxiety may further increase the rate of anxiety disorders in children with WS. Studies of children with TD have already demonstrated that the risk for anxiety disorders is higher for children of anxious parents than children of parents without anxiety (e.g., Dierker et al., 1999; Merikangas et al., 1999; Merikangas et al., 1998; Turner et al., 1998).

However, children with WS have a higher prevalence rate of anxiety disorder than that reported for children of anxious parents. An important focus for future research is to 
further investigate the separate and combined contributions of particular deleted gene(s) and history of maternal anxiety to anxiety in children with WS.

\section{Mothers of Children with WS}

Prevalence of anxiety disorders in mothers of children with WS. In this study, mothers of children with WS reported a significantly higher lifetime prevalence of GAD than women in the general population. Moreover, the difference remained significant when the mothers who had reported onset of anxiety disorders related to having a child with WS or raising a child with WS were excluded from the analyses. The mothers of children with WS also had a notably higher prevalence of anxiety disorders than mothers of children with Down syndrome and autism in previous studies (Piven et al., 1991; Piven \& Palmer 1991). However, the prevalence rate for GAD for mothers of children with WS prior to the birth of the child with WS (as reported by the mothers in retrospect) was comparable to that for women in the general population, suggesting that maternal GAD may be at least in part related to the stress of raising a child with WS.

Predictors of anxiety in mothers of children with WS. The model that predicted the presence of anxiety in mothers of children with WS included the WS child's sex, level of adaptive functioning, behavioral problems, and whether the mother was employed outside of home. Mothers who were not employed outside of the home had an increased likelihood of having an anxiety disorder relative to mothers who were employed outside of the home. This difference was not due to lower family income; family income in families where the mothers were employed was very similar to family income where the mothers were not employed. The other variable that significantly increased the odds of a mother having an anxiety disorder was the child with WS being a 
boy. This finding is consistent with that of Emerson (2003), who found that for mothers of children with $\mathrm{DD}$, having a boy with $\mathrm{DD}$ predicted negative psychological outcomes.

In the present study, child variables such as level of adaptive functioning or behavioral problems did not significantly affect the odds of a mother having an anxiety disorder. This is the first study to consider the relation between adaptive functioning or behavior disorders and maternal anxiety disorders. However, several studies have been conducted examining the relation between child adaptive functioning or behavior disorders and stress or related psychological outcomes. Fidler et al. (2000) found that behavioral problems were one of the strongest predictors of stress for parents of children with WS. Findings similar to those of Fidler et al. have been reported for parents of children with other types of DD (Baker, Blacher, Crnic, \& Edelbrock, 2002; Emerson, 2003a; Hastings, 2003; Weiss, Sullivan, \& Diamond, 2003). However, none of these studies examined maternal anxiety specifically, instead examining variables such as parental stress and psychological outcomes.

Summary. These findings demonstrate that maternal levels of GAD prior to the birth of the child with WS were similar to those for women in the general population. However, these rates rise significantly after the birth of the child, ending up much higher than for the general population. It is possible that this increase is related to the stress of raising a child with WS. This hypothesis is in part supported by the finding that mothers who are not employed outside of home are more likely to have an anxiety disorder. One question is why mothers of children with WS have increased prevalence of GAD rather than of other types of anxiety disorders. One possibility is that the diagnostic criteria of GAD (excessive worry or anxiety across a number of situations and events, which is 
difficult to control; APA, 2000) can encompass the stressors directly associated with raising a child with WS, such as health and school as well as stressors likely due to having a child with WS, but involving other family members, including spousal relations, parental relations with TD children and others. It is unclear what factors related to having a child with WS lead to an increase of GAD in the mothers. Future studies comparing prevalence rates of anxiety disorders in mothers of children with DD of varying etiologies may further explain these findings. Prospective studies of mothers of children with WS may also help outline the factors related to WS that affect prevalence of GAD in mothers.

\section{Siblings of Children with WS}

Prevalence of anxiety disorders in siblings of children with WS. In this study, the siblings of children with WS had the same prevalence of anxiety disorders as children in the general population as measured by Shaffer et al. (1996), with the exception of specific phobia. However, while the prevalence of specific phobia in siblings of children with WS was higher than that reported by Shaffer et al. (1996), it was similar to the rates reported in other studies of specific phobia in children with TD (Lichtenstein \& Annas, 2000; Muris \& Merckelbach, 2000). Lichtenstein and Annas (2000) examined the prevalence of specific phobia in 1106 pairs of 8-9 year old twins (both DZ and MZ), using a DSM-IV based questionnaire, and reported a rate of $8.6 \%$. Muris and Merckelbach (2000) administered the specific phobia sections of the DISC (Shaffer et al., 1996) to parents of 160 children aged $4-12$ years, reporting $17.6 \%$ prevalence of specific phobia. These findings suggest that the prevalence rate of specific phobia in the children in general population reported in Shaffer et al. (1996) may be an underestimate. 
In this case, the siblings of children with WS would not evidence increased prevalence of any anxiety disorder relative to children in the general population.

Predictors of anxiety in siblings of children with WS. Neither history of maternal anxiety nor any factors related to the sibling with WS, such as adaptive behavior, severity of anxiety disorder in the child with WS, or behavior problems, predicted or correlated with the presence of anxiety disorders in the siblings. These results may be due to the small number of siblings who had an anxiety disorder.

Summary. The siblings of children with WS appear to have prevalence of anxiety disorders similar to that found in the general population. A study with a larger number of siblings of children with WS who have anxiety may be successful at identifying predictors of anxiety in the siblings. Additionally, a comparison group of siblings of children with and without disabilities may help further clarify these findings.

\section{Implications for Genetic Research on Anxiety Disorders}

As described in the Introduction, research on complex disorders has demonstrated that examination of neurodevelopmental disorders of known genetic cause that are associated with high prevalence rates of a particular psychiatric disorder may be successful in identifying susceptibility genes for these disorders. For example, findings of elevated prevalence of schizophrenia in individuals with deletion 22q11 syndrome have prompted genetic linkage and association studies of schizophrenia on chromosome $22 q$, which has led to finding a potential schizophrenia susceptibility locus on chromosome 22q (reviewed in Murphy, 2002).

Thus far this approach has not been applied to anxiety disorders. The present study examined prevalence of anxiety disorders in WS, a neurodevelopmental disorder of 
a known genetic origin, establishing that its behavioral phenotype is associated with a significantly higher prevalence of anxiety disorders than in the general population. This finding indicates that there may be a causal relationship between anxiety and the deletion on chromosome 7q (Karayiorgou \& Gogos, 1994).

It is thus possible that there is a susceptibility locus for anxiety on $7 \mathrm{q} 11.23$. This possibility can be further tested by means of genetic linkage and association studies. From this point on several strategies may be implemented in order to identify how deletion 7q11.23 may contribute to anxiety. For example, deletion of one or more genes in the region deleted in WS may cause increased anxiety. To test this possibility, association studies may be conducted on genes contained in the deleted region, using samples of TD individuals with and without an anxiety disorder. It is also possible that the increased prevalence of anxiety in WS is due to the impact of the deletion of one or more genes in the deleted region on genes outside the deleted region that are involved in anxiety. To test this possibility, association studies on anxiety can be conducted with individuals with WS targeting genes that have already been implicated in anxiety. Although the findings of association studies of anxiety disorders are conflicting thus far, several genes may be of potential interest. COMT, an enzyme responsible for the metabolism of noradrenaline and dopamine, encoded by a gene located on 22q11 (Arnold et al., 2004) has been implicated in PD (Domschke et al., 2004) and OCD (Alsobrook et al., 2002). Another gene that may be of potential interest is a variant of the serotonin transporter (SERT) gene, implicated in personality traits related to anxiety (Lesch et al., 1996; Sen, Burmeister, \& Ghosh, 2004). Siblings and mothers of children with WS can 
serve as comparison groups in association studies, to control for differences not related to genetics, as suggested by Arnold et al. (2004).

\section{Conclusion}

This is the first study to examine familial aggregation of anxiety disorders in individuals with WS, a congenital disorder caused by a deletion of $\sim 25$ genes on chromosome $7 \mathrm{q} 11.23$, and their mothers and siblings, in comparison to the general population. These findings will in turn facilitate research on genes involved in anxiety. In addition, this study examined the roles of several potential predictors of anxiety in the probands with WS, their mothers, and their TD siblings.

Examination of prevalence rates of anxiety disorders in WS in this study demonstrates that children with WS have significantly higher rates of specific phobia, separation anxiety, and GAD in comparison to the general population. They also have significantly higher rates of specific phobia in comparison to their siblings closest in age, and although statistical analyses could not be conducted because of the low frequency of occurrence of other anxiety disorders, the children with WS had considerably higher rates of other anxiety disorders in comparison to their siblings as well. This finding in turn suggests that there may be a relationship between deletion $7 \mathrm{q} 11.23$ and anxiety disorders. As expected from findings for children in the general population, the odds of a child with WS having an anxiety disorder increased with age and with the severity of maternal anxiety. The mothers of children with WS have elevated rates of GAD in comparison to the general population of women. This increase may be related to stressors of raising a child with WS. The siblings did not have elevated rates of most anxiety disorders. No 
definitive conclusion could be made regarding whether the prevalence of specific phobia was significantly elevated in the sibling group.

Future studies will need to focus on further examining the prevalence of anxiety disorders in siblings of children with WS and their fathers in order to determine the impact of paternal anxiety on anxiety in children with WS. It will also be useful to conduct large scale comparison studies of anxiety disorders and their predictors in mothers and siblings of children with WS and other types of DD.

Given the increased prevalence of anxiety disorders in children with WS, genetic studies examining possible links between particular genes deleted in WS and anxiety are warranted. It would also be worthwhile to investigate possible relations between genes deleted in WS and genes outside the deleted region that have been previously implicated in anxiety disorders in the general population. Research in this area will yield valuable new findings for determining the etiology of anxiety disorders in the general population. 


\section{REFERENCES}

Abidin, R. R. (1995). Parenting Stress Index, 3rd Edition: Professional manual.

Odessa, FL: Psychological Assessment Resources, Inc.

Achenbach, T. M. (1991). Manual for the CBCL 4-18. Burlington: University of Vermont, Department of Psychiatry.

Achenbach, T. M., \& Edelbrock, C. (1983). Manual for the child behavior checklist and revised child behavior profile. Burlington: University of Vermont.

Achenbach, T. M., \& Rescorla, L. A. (2001a). Manual for ASEBA Preschool Forms and Profiles. Burlington: University of Vermont, Department of Psychiatry.

Achenbach, T. M., \& Rescorla, L. A. (2001b). Manual for the ASEBA School-Age Forms and Profiles. Burlington, VT: University of Vermont, Research Center for Children, Youth, and Families.

Achenbach, T. M., Conners, C. K., Quay, H. C., Verhulst, F. C., \& Howell, C. T. (1989). Replication of empirically derived syndromes as a basis for taxonomy of child/adolescent psychopathology. Journal of Abnormal Child Psychology, 17, 299-323.

Alsobrook, J. P., Zohar, A. H., Leboyer, M., Chabane, N., Ebstein, R. P., \& Pauls, D. L. (2002). Association between the COMT locus and obsessive-compulsive disorder in females but not males. American Journal of Medical Genetics, 114, 116-120. 
Ambrosini, P. J. (2000). Historical development and present status of the schedule for affective disorders and schizophrenia for school-age children (K-SADS). Journal of the American Academy of Child and Adolescent Psychiatry, 39, 49-58.

American Psychiatric Association. (1987). Diagnostic and Statistical Manual of Mental Disorders, 3rd Edition, Revised (DSM-III-R). Washington, DC: American Psychiatric Association.

American Psychiatric Association. (1994). Diagnostic and Statistical Manual of Mental Disorders, 4th Edition, (DSM-IV). Washington, D.C.: American Psychiatric Association.

American Psychiatric Association. (2000). Diagnostic and Statistical Manual of Mental Disorders, 4th Edition, Text Revision (DSM-IV-TR). Washington, D.C.: American Psychiatric Association.

Anderson, J. C., Williams, S., McGee, R., \& Silva, P. A. (1987). DSM-III disorders in preadolescent children. Prevalence in a large sample from the general population. Archives of General Psychiatry, 44, 69-76.

Andrews, G., Stewart, G., Allen, R., \& Henderson, A. S. (1990). The genetics of six neurotic disorders: a twin study. Journal of Affective Disorders, 19, 23-29.

Antshel, K. M., Fremont, W., Roizen, N. J., Shprintzen, R., Higgins, A. M., Dhamoon, A., \& Kates, W. (2006). ADHD, major depressive disorder, and simple phobias are prevalent psychiatric conditions in youth with Velocardiofacial syndrome. Journal of the American Academy of Child and Adolescent Psychiatry, 45, 596-603.

Arnold, P. D., Zai, G., \& Richter, M. A. (2004). Genetics of anxiety disorders. Current Psychiatry Reports, 6, 243-254. 
Backes, M., Genc, B., Schreck, J., Doerfler, W., Lehmkuhl, G., \& von Gontard, A. (2000). Cognitive and behavioral profile of fragile $\mathrm{X}$ boys: correlations to molecular data. American Journal of Medical Genetics A, 95, 150-156.

Baker, B. L., Blacher, J., Crnic, K. A., \& Edelbrock, C. (2002). Behavior problems and parenting stress in families of three-year-old children with and without developmental delays. American Journal of Mental Retardation, 107, 433-444.

Barlow, D. H., DiNardo, P. A., Vermilyea, B. B., Vermilyea, J., \& Blanchard, E. B. (1986). Co-morbidity and depression among the anxiety disorders. Issues in diagnosis and classification. Journal of Nervous and Mental Disease, 174, 63-72.

Bedford, A., \& Foulds, G. A. (1978). Delusions-Symptoms-States Inventory of Anxiety and Depression. Windsor, ON: National Foundation for Educational Research.

Belzer, K., \& Schneier, F. R. (2004). Comorbidity of anxiety and depressive disorders: issues in conceptualization, assessment, and treatment. Journal of Psychiatry Practice, 10, 296-306.

Benjamin, R. S., Costello, E. J., \& Warren, M. (1990). Anxiety disorders in a pediatric sample. Journal of Anxiety Disorders, 4, 293-316.

Bird, T. D., Jarvik, G. P., \& Wood, N. W. (2001). Genetic association studies: genes in search of diseases. Neurology, 57, 1153-1154.

Black, D. W., Noyes, R., Jr., Goldstein, R. B., \& Blum, N. (1992). A family study of obsessive-compulsive disorder. Archives of General Psychiatry, 49, 362-368.

Bolton, P. F., Pickles, A., Murphy, M., \& Rutter, M. (1998). Autism, affective and other psychiatric disorders: patterns of familial aggregation. Psychological Medicine, $28,385-395$. 
Bowen, R. C., Offord, D. R., \& Boyle, M. H. (1990). The prevalence of overanxious disorder and separation anxiety disorder: results from the Ontario Child Health Study. Journal of the American Academy of Child \& Adolescent Psychiatry, 29, 753-758.

Brown, E. C., Aman, M. G., \& Lecavalier, L. (2004). Empirical classification of behavioral and psychiatric problems in children and adolescents with mental retardation. American Journal on Mental Retardation, 109, 445-55

Brown, T. A., Di Nardo, P. A., Lehman, C. L., \& Campbell, L. A. (2001). Reliability of DSM-IV anxiety and mood disorders: implications for the classification of emotional disorders. Journal of Abnormal Psychology, 110, 49-58.

Brown, T. A., DiNardo, P. A., \& Barlow, D. H. (1994). Anxiety Disorders Interview Schedule (4th ed.). Boulder, CO: Graywind Publications.

Bruininks, R. H., Woodcock, R., Weatherman, R., \& Hill, B. (1996). Scales of Independent Behavior-Revised. Chicago, IL: Riverside.

Burke, K. C., Burke, J. D., Jr., Regier, D. A., \& Rae, D. S. (1990). Age at onset of selected mental disorders in five community populations. Archives of General Psychiatry, $47,511-518$.

Cadman, D., Boyle, M., \& Offord, D. R. (1988) The Ontario Child Health Study: social adjustment and mental health of siblings of children with chronic health problems. Journal of Developmental \& Behavioral Pediatrics, 9, 117-21.

Camarena, B., Aguilar, A., Loyzaga, C., \& Nicolini, H. (2004). A family-based association study of the 5-HT-1Dbeta receptor gene in obsessive-compulsive disorder. International Journal of Neuropsychopharmacology, 7, 49-53. 
Camp, N. J., Lowry, M. R., Richards, R. L., Plenk, A. M., Carter, C., Hensel, C. H., et al. (2005). Genome-wide linkage analyses of extended Utah pedigrees identifies loci that influence recurrent, early-onset major depression and anxiety disorders. American Journal of Medical Genetics B, 135, 85-93.

Carey, G., \& Gottesman, H. (1981). Twin and family studies of anxiety, phobic, and obsessive disorders. In D. F. Klein \& J. G. Rabking (Eds.), Anxiety: new research and changing concepts (pp. 117-136). New Tork: Raven Press.

Cherniske, E. M., Carpenter, T. O., Klaiman, C., Young, E., Bregman, J., Insogna, K., et al. (2004). Multisystem study of 20 older adults with Williams syndrome. American Journal of Medical Genetics A, 131, 255-264.

Cohen, J. (1992). A power primer. Psychological Bulletin, 112, 155-159

Coleby, M. (1995). The school-aged siblings of children with disabilities. Developmental Medicine and Child Neurology, 37, 415-426.

Cooper, S. A., Melville, C. A., Einfeld, S. L. (2003). Psychiatric diagnosis, intellectual disabilities and diagnostic criteria for psychiatric disorders for use with adults with learning disabilities/mental retardation (DC-LD). Journal of Intellectual and Developmental Disability Supplement 1, 3-15.

Crowe, R. R., Noyes, R., Jr., Wilson, A. F., Elston, R. C., \& Ward, L. J. (1987). A linkage study of panic disorder. Archives of General Psychiatry, 44, 933-937.

Crowe, R. R., Noyes, R., Pauls, D. L., \& Slymen, D. (1983). A family study of panic disorder. Archives of General Psychiatry, 40, 1065-1069.

Dekker, M. C. \& Koot, H. M. (2003). DSM-IV disorders in children with 
borderline to moderate intellectual disability. I: prevalence and impact. Journal of the American Academy of Child and Adolescent Psychiatry, 42, 915-22.

Dierker, L. C., Merikangas, K. R., \& Szatmari, P. (1999). Influence of parental concordance for psychiatric disorders on psychopathology in offspring. Journal of the American Academy of Child and Adolescent Psychiatry, 38, 280-288.

Di Nardo, P., Moras, K., Barlow, D. H., Rapee, R. M., \& Brown, T. A. (1993). Reliability of DSM-III-R anxiety disorder categories. Using the Anxiety Disorders Interview Schedule-Revised (ADIS-R). Archives of General Psychiatry, 50, 251-256.

Domschke, K., Freitag, C. M., Kuhlenbaumer, G., Schirmacher, A., Sand, P., Nyhuis, P., et al. (2004). Association of the functional V158M catechol-O-methyltransferase polymorphism with panic disorder in women. International Journal of Neuropsychopharmacology, 7, 183-188.

Donenberg, G., \& Baker, B. L. (1993). The impact of young children with externalizing behaviors on their families. Journal of Abnormal Child Psychology, 21, $179-198$

Dykens, E. M. (2000). Psychopathology in children with intellectual disability. Journal of Child Psychology and Psychiatry and Allied Disciplines, 41, 407-417.

Dykens, E. M. (2003). Anxiety, fears, and phobias in persons with Williams syndrome. Developmental Neuropsychology, 23, 291-316.

Dyson, L. L. (1999). The psychosocial functioning of school-age children who have siblings with developmental disabilities: change and stability over time. Journal of Applied Developmental Psychology, 20, 253-271

Edelbrock, C., Costello, A. J., Dulcan, M. K., Conover, N. C., Kalas, R. (1986). 
Parent-child agreement on child psychiatric symptoms assessed via structured interview. Journal of Child Psychology and Psychiatry and Allied Disciplines, 27, 181-90.

Edelbrock, C., Costello, A. J., Dulcan, M. K., Kalas, R., Conover, N. C. (1985). Age differences in the reliability of the psychiatric interview of the child. Child Development, 56, 265-275.

Einfeld, S., Tonge, B., \& Florio, T. (1997). Behavioral and emotional disturbance in individuals with Williams syndrome. American Journal on Mental Retardation, 102, $45-53$.

Einfeld, S., Tonge, B., \& Rees, V. (2001). Longitudinal course of behavioral and emotional problems in Williams syndrome. American Journal on Mental Retardation, $106,73-81$.

Einfeld, S., Tonge, B., Turner, G., Parmenter, T., \& Smith, A. (1999). Longitudinal course of behavioural and emotional problems of young persons with Prader-Willi, Fragile X, Williams and Down syndromes. Journal of Intellectual and Developmental Disability, 24, 349-354.

Einfeld, S. L., \& Tonge, B. J. (1995). The Developmental Behavior Checklist: The development and validation of an instrument to assess behavioral and emotional disturbance in children and adolescents with mental retardation. Journal of Autism and Developmental Disorders, 25, 81-104.

Elliott, C. D. (1990a). Differential Ability Scales. San Antonio TX: The Psychological Corporation.

Elliott, C. D. (1990b). Differential Ability Scales: Introductory and Technical Handbook. San Antonio TX: The Psychological Corporation. 
Emerson, E. (2003a). Mothers of children and adolescents with intellectual disability: Social and economic situation, mental health status, and the self-assessed social and psychological impact of the child's difficulties. Journal of Intellectual Disability Research, 47, 385-399.

Emerson, E. (2003b). Prevalence of psychiatric disorders in children and adolescents with and without intellectual disability. Journal of Intellectual Disability Research, 47, 51-58.

Erdal, M. E., Tot, S., Yazici, K., Yazici, A., Herken, H., Erdem, P., et al. (2003). Lack of association of catechol-O-methyltransferase gene polymorphism in obsessivecompulsive disorder. Depression and Anxiety, 18, 41-45.

Ewart, A. K., Morris, C. A., Atkinson, D., Jin, W., Sternes, K., Spallone, P., et al. (1993). Hemizygocity at the elastin locus in a developmental disorder. Williams syndrome. Nature Genetics, 5, 11-16.

Fidler, D. J., Hodapp, R. M., \& Dykens, E. M. (2002). Behavioral phenotypes and special education: Parent report of educational issues for children with Down syndrome, Prader-Willi syndrome, and Williams syndrome. Journal of Special Education, 36, 8088.

Finn, D. A., Rutledge-Gorman, M. T., \& Crabbe, J. C. (2003). Genetic animal models of anxiety. Neurogenetics, 4, 109-135.

Fisman, S., Wolf, L., Ellison, D., Gillis, B., Freeman, T., \& Szatmari, P. (1996). Risk and protective factors affecting the adjustment of siblings of children with chronic disabilities. Journal of the American Academy of Child and Adolescent Psychiatry, 35, $1532-1541$. 
Flint, J. (1998). Behavioral phenotypes: conceptual and methodological issues. American Journal of Medical Genetics, 81, 235-240.

Ford, T., Goodman, R., \& Meltzer, H. (2003). The British Child and Adolescent Mental Health Survey 1999: the prevalence of DSM-IV disorders. Journal of the American Academy of Child and Adolescent Psychiatry, 42, 1203-1211.

Fyer, A. J., Mannuzza, S., Chapman, T. F., Lipsitz, J., Martin, L. Y., \& Klein, D. F. (1996). Panic disorder and social phobia: effects of comorbidity on familial transmission. Anxiety, 2, 173-178.

Fyer, A. J., Mannuzza, S., Chapman, T. F., Martin, L. Y., \& Klein, D. F. (1995). Specificity in familial aggregation of phobic disorders. Archives of General Psychiatry, $52,564-573$.

Fyer, A. J., Mannuzza, S., Gallops, M. S., Martin, L. Y., Aaronson, C., Gorman, J. M., et al. (1990). Familial transmission of simple phobias and fears. A preliminary report. Archives of General Psychiatry, 47, 252-256.

Gelernter, J., Bonvicini, K., Page, G., Woods, S. W., Goddard, A. W., Kruger, S., et al. (2001). Linkage genome scan for loci predisposing to panic disorder or agoraphobia. American Journal of Medical Genetics A, 105, 548-557.

Gelernter, J., Page, G. P., Bonvicini, K., Woods, S. W., Pauls, D. L., \& Kruger, S. (2003). A chromosome 14 risk locus for simple phobia: results from a genomewide linkage scan. Molecular Psychiatry, 8, 71-82.

Gelernter, J., Page, G. P., Stein, M. B., \& Woods, S. W. (2004). Genome-wide linkage scan for loci predisposing to social phobia: evidence for a chromosome 16 risk locus. American Journal of Psychiatry, 161, 59-66. 
Goodman, W. K., Rasmussen, S. A., Price, L. H., \& Rapoport, J. L. (1986). Children's Yale-Brown Obsessive-Compulsive Scale. Gainesville, FL: University of Florida.

Gosch, A., \& Pankau, R. (1997). Personality characteristics and behaviour problems in individuals of different ages with Williams syndrome. Developmental Medicine \& Child Neurology, 39, 527-533.

Gutierrez, B., Arias, B., Gasto, C., Catalan, R., Papiol, S., Pintor, L., et al. (2004). Association analysis between a functional polymorphism in the monoamine oxidase A gene promoter and severe mood disorders. Psychiatric Genetics, 14, 203-208.

Hamilton, S. P., Fyer, A. J., Durner, M., Heiman, G. A., Baisre de Leon, A., Hodge, S. E., et al. (2003). Further genetic evidence for a panic disorder syndrome mapping to chromosome 13q. Proceeding of the National Academy of Sciences, 100, 2550-2555.

Hanna, G. L., Himle, J. A., Curtis, G. C., \& Gillespie, B. W. (2005). A family study of obsessive-compulsive disorder with pediatric probands. American Journal of Medical Genetics: Neuropsychiatric Genetics, 134, 13-19.

Hanna, G. L., Veenstra-VanderWeele, J., Cox, N. J., Boehnke, M., Himle, J. A., Curtis, G. C., et al. (2002). Genome-wide linkage analysis of families with obsessivecompulsive disorder ascertained through pediatric probands. American Journal of Medical Genetics B, 114, 541-552.

Harris, E. L., Noyes, R., Jr., Crowe, R. R., \& Chaudhry, D. R. (1983). Family study of agoraphobia. Report of a pilot study. Archives of General Psychiatry, 40, 10611064. 
Harvey, J. M., O'Callaghan, M. J., \& Vines, B. (1997). Prevalence of maternal depression and its relationship to $\mathrm{ADL}$ skills in children with developmental delay. Journal of Paediatric Child Health, 33, 42-46.

Hastings, R. P. (2002). Parental stress and behaviour problems of children with developmental disability. Journal of Intellectual \& Developmental Disability, 27, 149160.

Helzer, J. E., Robins, L. N., \& McEvoy, L. (1987). Post-traumatic stress disorder in the general population. Findings of the epidemiologic catchment area survey. New England Journal of Medicine, 317, 1630-1634.

Hemmings, S. M., Kinnear, C. J., Niehaus, D. J., Moolman-Smook, J. C., Lochner, C., Knowles, J. A., et al. (2003). Investigating the role of dopaminergic and serotonergic candidate genes in obsessive-compulsive disorder. European Neuropsychopharmacology, 13, 93-98.

Hettema, J. M., Neale, M. C., \& Kendler, K. S. (2001). A review and metaanalysis of the genetic epidemiology of anxiety disorders. American Journal of Psychiatry, 158, 1568-1578.

Hettema, J. M., Prescott, C. A., \& Kendler, K. S. (2001). A population-based twin study of generalized anxiety disorder in men and women. Journal of Nervous and Mental Disease, $189,413-420$.

Horwath, E., Wolk, S. I., Goldstein, R. B., Wickramaratne, P., Sobin, C., Adams, P., et al. (1995). Is the comorbidity between social phobia and panic disorder due to familial cotransmission or other factors? Archives of General Psychiatry, 52, 574-582. 
Inada, Y., Yoneda, H., Koh, J., Sakai, J., Himei, A., Kinoshita, Y., et al. (2003). Positive association between panic disorder and polymorphism of the serotonin $2 \mathrm{~A}$ receptor gene. Psychiatry Research, 118, 25-31.

Ise, K., Akiyoshi, J., Horinouchi, Y., Tsutsumi, T., Isogawa, K., \& Nagayama, H. (2003). Association between the CCK-A receptor gene and panic disorder. American Journal of Medical Genetics B, 118, 29-31.

Karayiorgou, M., \& Gogos, J. A. (1997). A turning point in schizophrenia genetics. Neuron, 19, 967-979.

Karno, M., \& Golding, J. M. (1991). Obsessive compulsive disorder. In L. N. Robins \& D. A. Regier (Eds), Psychiatric disorders in America (pp. 204-219). New York: Free Press.

Karno, M., Golding, J. M., Sorenson, S. B., \& Burnam, M. A. (1988). The epidemiology of obsessive-compulsive disorder in five US communities. Archives of General Psychiatry, 45, 1094-1099.

Kendall, P. C., Chansky, T. E., Kane, M. T., Kortlander, E., Ronan, K., Sessa, F. M., et al. (1993). Anxiety disorders in youth. Boston: Allin and Bacon.

Kendler, K. S. (1997). The genetic epidemiology of psychiatric disorders: a current perspective. Social Psychiatry and Psychiatric Epidemiology, 32, 5-11.

Kendler, K. S., Myers, J., Prescott, C. A., \& Neale, M. C. (2001). The genetic epidemiology of irrational fears and phobias in men. Archives of General Psychiatry, 58, $257-265$.

Kendler, K. S., Neale, M. C., Kessler, R. C., Heath, A. C., \& Eaves, L. J. (1992). The genetic epidemiology of phobias in women. The interrelationship of agoraphobia, 
social phobia, situational phobia, and simple phobia. Archives of General Psychiatry, 49, $273-281$.

Kendler, K. S., Neale, M. C., Kessler, R. C., Heath, A. C., \& Eaves, L. J. (1993). Panic disorder in women: a population-based twin study. Psychological Medicine, 23, 397-406.

Kennedy, J. L., Neves-Pereira, M., King, N., Lizak, M. V., Basile, V. S., Chartier, M. J., et al. (2001). Dopamine system genes not linked to social phobia. Psychiatric Genetics, 11, 213-217.

Kessler R. C., Berglund, P., Demler, O., Jin, R., Merikangas, K., \& Walters, E. E. (2005). Lifetime prevalence and age of onset distributions of DSM-IV disorders in the National Comorbidity Survey Replication. Archives of General Psychiatry, 62, 593-602.

Kessler, R. C., DuPont, R. L., Berglund, P., \& Wittchen, H. U. (1999). Impairment in pure and comorbid generalized anxiety disorder and major depression at 12 months in two national surveys. American Journal of Psychiatry, 156, 1915-1923.

Kessler, R. C., McGonagle, K. A., Zhao, S., Nelson, C. B., Hughes, M., Eshleman, S., et al. (1994). Lifetime and 12-month prevalence of DSM-III-R psychiatric disorders in the United States: results from the National Comorbidity Survey. Archives of General Psychiatry, 51, 8-19.

Kessler, R. C., Sonnega, A., Bromet, E., Hughes, M., \& Nelson, C. B. (1995). Posttraumatic stress disorder in the National Comorbidity Survey. Archives of General Psychiatry, 52, 1048-1060. 
Klein-Tasman, B. P., \& Mervis, C. B. (2003). Distinctive personality characteristics of 8-, 9-, and 10-year-olds with Williams syndrome. Developmental Neuropsychology, 23, 269-290.

Knowles, J. A., Fyer, A. J., Vieland, V. J., Weissman, M. M., Hodge, S. E., Heiman, G. A., et al. (1998). Results of a genome-wide genetic screen for panic disorder. American Journal of Medical Genetics B, 81, 139-147.

Kunugi, H., Ishida, S., Kato, T., Tatsumi, M., Sakai, T., Hattori, M., et al. (1999). A functional polymorphism in the promoter region of monoamine oxidase-A gene and mood disorders. Molecular Psychiatry, 4, 393-395.

Lawford, B. R., Mc, D. Y. R., Noble, E. P., Kann, B., Arnold, L., Rowell, J., et al. (2003). D2 dopamine receptor gene polymorphism: paroxetine and social functioning in posttraumatic stress disorder. European Neuropsychopharmacology, 13, 313-320.

Lenhard, W., Breitenbach, E., Ebert, H., Schindelhauer-Deutscher, H. J., \& Henn, W. (2005). Psychological benefit of diagnostic certainty for mothers of children with disabilities: lessons from Down syndrome. American Journal of Medical Genetics A, $133,170-175$.

Lesch, K. P., Bengel, D., Heils, A., Sabol, S., Greenberg, B., Petri, J. et al. (1996) Association of anxiety-related traits with a polymorphism in the serotonin transporter gene regulatory region. Science, 274, 1527-1531.

Leyfer, O., Woodruff-Borden, J., Fricke, J., \& Mervis, C. B. (2004). Prevalence of psychiatric disorders in children with Williams Syndrome. Paper presented at the 10th International Professional Conference on Williams Syndrome, Grand Rapids, MI. 
Leyfer, O., Woodruff-Borden, J., Klein-Taskam, B. P., Fricke, J., \& Mervis, C. B. (2006). Prevalence of psychiatric disorders in 4 to 16-year-olds with Williams syndrome. American Journal of Medical Genetics B, 141, 615-622.

Lichtenstein, P., \& Annas, P. (2000). Heritability and prevalence of specific fears and phobias in childhood. Journal of Child Psychology and Psychiatry and Allied Disciplines, 41, 927-937.

Lochner, C., Hemmings, S. M., Kinnear, C. J., Moolman-Smook, J. C., Corfield, V. A., Knowles, J. A., et al. (2004). Corrigendum to "gender in obsessive-compulsive disorder: clinical and genetic findings" European Neuropsychopharmacology, 14, 437445.

Lord, C., Risi, S., Lambrecht, L., Cook, E., Leventhal, B., DiValore, P., Pickles, A., \& Rutter, M. (2000). The Autism Diagnostic Observation Schedule-Generic: a standard measure of social and communication deficits associated with the spectrum of autism. Journal of Autism and Developmental Disorders, 30, 205-223.

Lord, C., Rutter, M., \& Le Couteur, A. (1994). Autism Diagnostic InterviewRevised: a revised version of a diagnostic interview for caregivers of individuals with possible pervasive developmental disorders. Journal of Autism and Developmental Disorders, 24, 659-85.

Maier, W., Lichtermann, D., Minges, J., Oehrlein, A., \& Franke, P. (1993). A controlled family study in panic disorder. Journal of Psychiatric Research, 27 Suppl 1, 79-87.

McHale, S.M., \& Gamble, W.C. (1989). Sibling relationships with disabled and non-disabled brothers and sisters. Developmental Psychology, 25, 421-429. 
Mendlewicz, J., Papadimitrou, G., \& Wilmotte, J. (1993). Family study of panic disorder: comparison with generalized anxiety disorder, major depressive disorder and normal subjects. Psychiatric Genetics, 3, 73-78.

Meng, X.L., Rosenthal, R., \& Rubin, D.B. (1992). Comparing correlated correlation coefficients. Psychological Bulletin, 111, 172-175

Merikangas, K. R., Avenevoli, S., Dierker, L., \& Grillon, C. (1999). Vulnerability factors among children at risk for anxiety disorders. Biological Psychiatry, 46, 15231535.

Merikangas, K. R., Swendsen, J. D., Preisig, M. A., \& Chazan, R. Z. (1998). Psychopathology and temperament in parents and offspring: results of a family study. Journal of Affective Disorders, 51, 63-74.

Mervis, C. B., Robinson, B. F., Bertrand, J., Morris, C. A., Klein-Tasman, B. P., \& Armstrong, S. C. (2000). The Williams syndrome cognitive profile. Brain and Cognition, 44, 604-628.

Meyer-Lindenberg, A., Mervis, C. B., \& Berman, K. F. (2006). Neural mechanisms in Williams syndrome: a unique window to genetic influences on cognition and behavior. Nature Reviews: Neuroscience, 7, 380-393

Miyasaka, K., Yoshida, Y., Matsushita, S., Higuchi, S., Shirakawa, O., Shimokata, H., et al. (2004). Association of cholecystokinin-A receptor gene polymorphisms and panic disorder in Japanese. American Journal of Medical Genetics B, $127,78-80$. 
Morris, C. A. (2005). Williams syndrome. In S. B. Cassidy \& J. E. Allanson (Eds.), Management of genetic syndromes (2nd ed., pp. 655-667). New York: Wiley \& Sons.

Munafo, M. R., \& Flint, J. (2004). Meta-analysis of genetic association studies. Trends in Genetics, 20, 439-444.

Muris, P., \& Merckelbach, H. (2000). How serious are common childhood fears? II. The parent's point of view, Behaviour Research and Therapy 38, 813-818.

Murphy, K. C. (2002). Schizophrenia and velo-cardio-facial syndrome. Lancet, $359,426-430$.

Murphy, K. C., \& Owen, M. J. (2001). Velo-cardio-facial syndrome: a model for understanding the genetics and pathogenesis of schizophrenia. British Journal Psychiatry, 179, 397-402.

Myers, B. A., \& Pueschel, S. M. (1991). Psychiatric disorders in persons with Down syndrome. Journal of Nervous and Mental Disorders, 179, 609-613.

Neale, M. C., Walters, E. E., Eaves, L. J., Kessler, R. C., Heath, A. C., \& Kendler, K. S. (1994). Genetics of blood-injury fears and phobias: a population-based twin study. American Journal of Medical Genetics, 54, 326-334.

Nestadt, G., Samuels, J., Riddle, M., Bienvenu, O. J., 3rd, Liang, K. Y., LaBuda, M., et al. (2000). A family study of obsessive-compulsive disorder. Archives of General Psychiatry, 57, 358-363.

Nihira, K., Leland, H., \& Lambert, N. (1993). AAMD Adaptive Behavior Scale Residential and Community. Austin, TX: Pro-Ed. 
Noyes, R., Jr., Clarkson, C., Crowe, R. R., Yates, W. R., \& McChesney, C. M. (1987). A family study of generalized anxiety disorder. American Journal of Psychiatry, 144, 1019-1024.

Noyes, R., Jr., Crowe, R. R., Harris, E. L., Hamra, B. J., McChesney, C. M., \& Chaudhry, D. R. (1986). Relationship between panic disorder and agoraphobia. A family study. Archives of General Psychiatry, 43, 227-232.

Osborne, L. R. (2006). The molecular basis of a multisystem disorder. In C. A. Morris, H. M. Lenhoff, \& P. P. Wang (Eds.), Williams-Beuren syndrome: Research, evaluation, and treatment (pp. 18-58). Baltimore, MD: Johns Hopkins University Press.

Pauls, D. L., Alsobrook, J. P., 2nd, Goodman, W., Rasmussen, S., \& Leckman, J. F. (1995). A family study of obsessive-compulsive disorder. American Journal of Psychiatry, 152, 76-84.

Perna, G., Caldirola, D., Arancio, C., \& Bellodi, L. (1997). Panic attacks: a twin study. Psychiatry Research, 66, 69-71.

Piven, J., Chase, G. A., Landa, R., Wzorek, M., Gayle, J., Cloud, D., et al. (1991). Psychiatric disorders in the parents of autistic individuals. Journal of the American Academy of Child \& Adolescent Psychiatry, 30, 471-478.

Piven, J., \& Palmer, P. (1999). Psychiatric disorder and the broad autism phenotype: evidence from a family study of multiple-incidence autism families. American Journal of Psychiatry, 156, 557-563.

Reddy, P. S., Reddy, Y. C., Srinath, S., Khanna, S., Sheshadri, S. P., \& Girimaji, S. R. (2001). A family study of juvenile obsessive-compulsive disorder. Canadian Journal of Psychiatry, 46, 346-351. 
Reiss, S., Levitan, G. W., \& Szyszko, J. (1982). Emotional disturbance and mental retardation: diagnostic overshadowing. American Journal of Mental Deficiency, $86,567-74$

Reynolds, C. R., \& Kamphaus, R. W. (1992). Behavior Assessment System for Children. Circle Pines, MN: American Guidance Service, Inc.

Reynolds, C. R., \& Richmond, B. O. (1985). Revised Children's Manifest AnxietyScale. Los Angeles: Western Psychological Services.

Risch, N., \& Merikangas, K. (1996). The future of genetic studies of complex human diseases. Science, 273, 1516-1517.

Rothbart, M. K., \& Ahadi, S. A. (1994). Temperament and the development of personality. Journal of Abnormal Psychology, 103, 55-66.

Rothe, C., Gutknecht, L., Freitag, C., Tauber, R., Mossner, R., Franke, P., et al. (2004). Association of a functional 1019C $>$ G 5-HT1A receptor gene polymorphism with panic disorder with agoraphobia. International Journal of Neuropsychopharmacology, 7 , 189-192.

Scherrer, J. F., True, W. R., Xian, H., Lyons, M. J., Eisen, S. A., Goldberg, J., et al. (2000). Evidence for genetic influences common and specific to symptoms of generalized anxiety and panic. Journal of Affective Disorders, 57, 25-35.

Schupf, N., \& Sergievsky, G. H. (2002). Genetic and host factors for dementia in Down's syndrome. British Journal of Psychiatry, 180, 405-410.

Sen, S., Burmeister, M., \& Ghosh, D. (2004). Meta-analysis of the association between a serotonin transporter promoter polymorphism (5-HTTLPR) and anxietyrelated personality traits. American Journal of Medical Genetics B, 127, 85-89. 
Shaffer, D., Fisher, P., Dulcan, M. K., Davies, M., Piacentini, J., Schwab-Stone, M. E., et al. (1996). The NIMH Diagnostic Interview Schedule for Children Version 2.3 (DISC-2.3): description, acceptability, prevalence rates, and performance in the MECA Study. Methods for the Epidemiology of Child and Adolescent Mental Disorders Study. Journal of the American Academy of Child and Adolescent Psychiatry, 35, 865-877.

Sheskin, D. J. (2000). Handbook of parametric and nonparametric statistical procedures ( $2^{\text {nd }}$ ed.). Boca Raton: Chapman \& Hall, 2000.

Silverman, W. K. (1994). Structured diagnostic interviews. In T.H. Ollendick, N.J. King, \& W. Yule (Eds.) International handbook of phobic and anxiety disorders in children and adolescents: issues in clinical child psychology (pp. 293-315). New York: Plenum Press.

Silverman, W. K., \& Albano, A. M. (1996). The Anxiety Disorders Interview Schedule for DSM-IV: parent interview schedule. San Antonio, TX: Graywind Publications, a Division of the Psychological Corporation.

Silverman, W. K., Saavedra, L. M., \& Pina, A. A. (2001). Test-retest reliability of anxiety symptoms and diagnoses with the Anxiety Disorders Interview Schedule for DSM-IV: child and parent versions. Journal of the American Academy of Child and Adolescent Psychiatry, 40, 937-44.

Skre, I., Onstad, S., Torgersen, S., Lygren, S., \& Kringlen, E. (1993). A twin study of DSM-III-R anxiety disorders. Acta Psychiatrica Scandinavica, 88, 85-92.

Smoller, J. W., Acierno, J. S., Jr., Rosenbaum, J. F., Biederman, J., Pollack, M. H., Meminger, S., et al. (2001). Targeted genome screen of panic disorder and anxiety 
disorder proneness using homology to murine QTL regions. American Journal of Medical Genetics B, 105, 195-206.

Smoller, J. W., Finn, C., \& White, C. (2000). The genetics of anxiety disorders: an overview. Psychiatric Annals, 30, 745-753.

Smoller, J. W., \& Tsuang, M. T. (1998). Panic and phobic anxiety: defining phenotypes for genetic studies. American Journal of Psychiatry, 155, 1152-1162.

Sovner, R. (1986). Limiting factors in the use of DSM-III criteria with mentally ill/mentally retarded persons. Psychopharmacology Bulletin, 22, 1055-1059.

Sovner, R., \& Hurley, A. D. (1983). Do the mentally retarded suffer from affective illness? Archives of General Psychiatry, 40, 61-67.

Sovner, R., \& Hurley, A. D. (1982a). Diagnosing depression in the mentally $r$ retarded. Psychological Aspects of Mental Retardation, 1, 1-4.

Sovner, R., \& Hurley, A. D. (1982b). Diagnosing mania in the mentally retarded. Psychological Aspects of Mental Retardation, 1, 10-12.

Spanbergerg, J. J., \& Theron, J. C. (2001). Stress and coping in parents of children with Down syndrome. Studia Psychologica, 43, 41-48.

Spielberger, C. D. (1983). Manual for the State-Trait Anxiety Inventory (STAI). PaloAlto, CA: Consulting Psychologists Press.

Spitzer, R. L., \& Endicott, J. (1978). Schedule for Affective Disorders and Schizophrenia. NIMH Clinical Research Branch, Collaborative Program on the Psychology of Depression, Washington, DC: U.S. Government Printing Office. 
Stein, M. B., Chartier, M. J., Hazen, A. L., Kozak, M. V., Tancer, M. E., Lander, S., et al. (1998). A direct-interview family study of generalized social phobia. American Journal of Psychiatry, 155, 90-97.

Stein, M. B., Chartier, M. J., Kozak, M. V., King, N., \& Kennedy, J. L. (1998). Genetic linkage to the serotonin transporter protein and 5HT2A receptor genes excluded in generalized social phobia. Psychiatry Research, 81, 283-291.

Switaj, D. M. (2000). Identification and measurement of anxiety and obsessivecompulsive tendencies in the Williams syndrome behavioral phenotype. Dissertation Abstracts International: Section B: The Sciences \& Engineering, 61, 1622. US: University Microfilms International.

Tadic, A., Rujescu, D., Szegedi, A., Giegling, I., Singer, P., Moller, H. J., et al. (2003). Association of a MAOA gene variant with generalized anxiety disorder, but not with panic disorder or major depression. American Journal of Medical Genetics B, 117, $1-6$.

Tellegen, A. (1985). Structures of mood and personality and their relevance to assessing anxiety, with an emphasis on self-report. In A.H. Tuma \& J.D. Maser (Eds.), Anxiety and the anxiety disorders (pp. 681-716). Hillsdale, NJ: Lawrence Erlbaum Associates, Inc.

Thorgeirsson, T. E., Oskarsson, H., Desnica, N., Kostic, J. P., Stefansson, J. G., Kolbeinsson, H., et al. (2003). Anxiety with panic disorder linked to chromosome 9q in Iceland. American Journal of Human Genetics, 72, 1221-1230.

Tonge, B., \& Einfeld, S. (2003). Psychopathology and intellectual disability: The Australian Child to Adult Longitudinal Study. In L. M. Glidden (Ed.), International 
review of research in mental retardation. (vol. 27, pp. 61-91). San Diego, CA: Elsevier Science.

Torgersen, S. (1983). Genetic factors in anxiety disorders. Archives of General Psychiatry, 40, 1085-1089.

Turner, S. M., Beidel, D. C., \& Costello, A. (1987). Psychopathology in the offspring of anxiety disorders patients. Journal of Consulting and Clinical Psychology, $55,229-235$.

Udwin, O., \& Yule, W. (1991). A cognitive and behavioural phenotype in Williams syndrome. Journal of Clinical and Experimental Neuropsychology, 13, 232244.

Udwin, O., Yule, W., \& Martin, N. (1987). Cognitive abilities and behavioural characteristics of children with idiopathic infantile hypercalcaemia. Journal of Child Psychology and Psychiatry and Allied Disciplines, 28, 297-309.

van West, D., \& Claes, S. (2004). The genetics of panic disorder: state of the art. Acta neuropsychiatrica, 16, 68-78.

Verhulst, F. C., van der Ende, J., Ferdinand, R. F., \& Kasius, M. C. (1997). The prevalence of DSM-III-R diagnoses in a national sample of Dutch adolescents. Archives of General Psychiatry, 54, 329-336.

Weiss, J. A., Sullivan, A., \& Diamond, T. (2003). Parent stress and adaptive functioning of individuals with developmental disabilities. Journal on Developmental Disabilities, 10, 129-135. 
Weissman, M. M., Fyer, A. J., Haghighi, F., Heiman, G., Deng, Z., Hen, R., et al. (2000). Potential panic disorder syndrome: clinical and genetic linkage evidence. American Journal of Medical Genetics, 96, 24-35.

Weissman, M. M., Wickramaratne, P., Adams, P. B., Lish, J. D., Horwath, E., Charney, D., et al. (1993). The relationship between panic disorder and major depression. A new family study. Archives of General Psychiatry, 50, 767-780.

Woodman, C. L. (1993). The genetics of panic disorder and generalized anxiety disorder. Annals of Clinical Psychiatry, 5, 231-239. 


\title{
CURRICULUM VITAE
}

\author{
Ovsanna Leyfer \\ Department of Psychological and Brain Sciences \\ University of Louisville \\ Louisville, KY 40292 \\ Email:o.leyfer@louisville.edu
}

\section{EDUCATION}

\section{University of Louisville}

Louisville, KY

Ph.D., Clinical Psychology

2007 (anticipated graduation)

M.A., Clinical Psychology

2005

Tufts University

Medford, MA

M.A., Child Development, Clinical Psychology Track 2001

\section{Allegheny College}

Meadville, PA

B.A. Cum Laude, Psychology

1999

\section{PUBLICATIONS}

Ballash, N. G., Leyfer, O. T., Buckley, A. F., \& Woodruff-Borden, J. (2006). A developmental analysis of parental control in the etiology of anxiety. Clinical Child and Family Psychology Review, 9, 113-133.

Leyfer, O. T., Folstein, S. E., Bacalman, S., Davis, N. O., Dinh, E., Morgan, J., TagerFlusberg, H., \& Lainhart, J. E. (2006). Comorbid psychiatric disorders in children with autism: interview development and rates of disorders. Journal of Autism and Developmental Disorders, 36, 849-861.

Leyfer, O. T., Ruberg, J., \& Woodruff-Borden, J. (2006). Examination of the utility of the Beck Anxiety Inventory and its factors as a screener for anxiety disorders. Journal of Anxiety Disorders, 20, 444-458. 
Leyfer, O. T., Woodruff-Borden, J., Klein-Tasman, B. P., Fricke, J., \& Mervis, C. B. (2006). Prevalence of psychiatric disorders in 4 to 16-year-olds with Williams syndrome. American Journal of Medical Genetics, 141B, 615-622.

Woodruff-Borden, J. \& Leyfer, O. T. (2006). Anxiety and fear. In M. Hersen (Ed.), Clinical Handbook of Behavioral Assessment, (Vol. 1, pp. 267-289). New York: Academic Press.

Tadevosyan-Leyfer, O., Dowd, M., Mankoski, R., Winkloski, B., Putnam, S., TagerFlusberg, H., McGrath, L., \& Folstein, S. E. (2003) A discriminant factor analysis of the Autism Diagnostic Interview-Revised. Journal of the American Academy of Child and Adolescent Psychiatry, 42, 864-872.

Nurmi, E., Dowd, M., Tadevosyan-Leyfer, O., Haines, J., Folstein, S. E., \& Sutcliffe, J. (2003). Subsetting autism families based on savant skills improves evidence of genetic linkage to 15q11-q13. Journal of the American Academy of Child and Adolescent Psychiatry, 42, 856863.

Folstein S. E., Dowd, M., Mankoski, R., \& Tadevosyan, O. (2003). How might genetic mechanisms operate in autism? In G. Bock (Ed.) Autism: neural basis and treatment possibilities (pp. 70-80). Chichester, UK: John Wiley and Sons.

Tadevosyan, O. (2000). The effects of foreign language learning on first language skill in children with mental retardation. In E. Protassova (Ed.) Helsinki Symposium on Child Bilingualism Bilingualism and Education, (Vol. 1, pp. 146-150). Helsinki, Finland: University of Helsinki.

\section{RESEARCH PRESENTATIONS}

Leyfer, O., Buckley, A. F., Zurlage, M. M., Mitchell, C. K., Shaw, M. A., Newton, T. L., \& Woodruff-Borden, J. (2006). Clinical characteristics of younger versus older adults in a medically underserved primary care setting. Presented at the $39^{\text {th }}$ Annual Convention of the Association for Advancement of Behavior Therapy, Chicago, IL.

Zurlage, M. M., Leyfer, O., Buckley, A., Shaw, A., Mitchell, C., Newton, T., \& Woodruff-Borden, J. (2006). The relationship between self-reported anxiety and smoking in primary care. Presented at the $39^{\text {th }}$ Annual Convention of the Association for Advancement of Behavior Therapy, Chicago, IL.

Leyfer, O., Woodruff-Borden, J., \& Mervis, C. B. (2006). Anxiety disorders in children with Williams syndrome, their mothers, and their siblings: Implications for the etiology of anxiety disorders. Presented at the $11^{\text {th }}$ International Professional Conference on Williams Syndrome, Richmond, VA. 
Leyfer, O., Phillips, K. D., Kistler, D. J., Klein-Tasman, B. P., Woodruff-Borden, J., \& Mervis, C. B. (2006). Exploratory factor analysis and factor validity of the Child Behavior Checklist for children with Williams syndrome. Presented at the $11^{\text {th }}$ International Professional Conference on Williams Syndrome, Richmond, VA.

Leyfer, O., Phillips, K. D., Kistler, D. J., Klein-Tasman, B. P., Woodruff-Borden, J., \& Mervis, C. B. (2005). The Children's Behavior Questionnaire: Factor validity study for children with Williams syndrome. Presented at the $39^{\text {th }}$ Annual Convention of the Association for Advancement of Behavior Therapy, Washington, DC.

Leyfer, O., Harvison, K., \& Woodruff-Borden, J. (2005). The relationship between maternal anxiety and child effortful control. Presented at the $39^{\text {th }}$ Annual Convention of the Association for Advancement of Behavior Therapy, Washington, DC. Thomas, T. N., Leyfer, O., \& Woodruff-Borden, J. (2005). The relationship between ethnicity and maternal sensitivity. Presented at the $39^{\text {th }}$ Annual Convention of the Association for Advancement of Behavior Therapy, Washington, DC.

Leyfer, O. (2005). Making DSM-IV diagnoses in Williams syndrome using Anxiety Disorders Interview Schedule. Presented at the Genetic Research Symposium, Las Vegas, NV.

Ruberg, J.L., Leyfer, O., Wodruff-Borden, J. (2005). An examination of the utility of the $B A I$ and BAI-PC for detecting panic disorder in primary care settings. Presented at the Society of Behavioral Medicine $25^{\text {th }}$ Annual Meeting, Boston, MA.

Leyfer, O., Ballash, N. G., Pemble, M. K., \& Woodruff-Borden, J. (2004). Relationship between mother's anxiety and maternal sensitivity. Presented at the $38^{\text {th }}$ Annual

Convention

of the Association for Advancement of Behavior Therapy, New Orleans, LA.

Ruberg, J.L., Leyfer, O., Brewer, V. B., Woodruff-Borden, J. (2004). Anxiety Disorders Interview Schedule: Parent-child agreement. Presented at the $38^{\text {th }}$ Annual Convention of the Association for Advancement of Behavior Therapy, New Orleans, LA.

Ballash, N. G., Pemble, M. K., Leyfer, O., Harvison, K., Woodruff-Borden, J. (2004) Life stress and anxiety. Presented at the $38^{\text {th }}$ Annual Convention of the Association for Advancement of Behavior Therapy, New Orleans, LA.

Leyfer, O., Woodruff-Borden, J., \& Mervis, C. B. (2004) Prevalence of psychiatric disorders in children with Williams Syndrome. Presented at the $10^{\text {th }}$ International Professional Conference on Williams Syndrome, Grand Rapids, MI.

Leyfer, O., Woodruff-Borden, J., \& Mervis, C. B. (2004). The Anxiety Disorders Interview Schedule, Parent versions: data from children with Williams Syndrome. Presented at the $24^{\text {th }}$ Annual Conference of the Anxiety Disorders Association of America, Miami, FL. 
Tadevosyan, O., Folstein, S. E., Lainhart, J. (2002). The K-SADS-DD-PL - a psychiatric diagnostic instruments for persons with developmental disorders. Presented at the $92^{\text {nd }}$ Annual meeting of the American Psychopathological Association Conference, New York, NY.

McGrath, L., Joseph, R., Tadevosyan, O., Folstein, S. E., Tager-Flusberg, H. (2002). Overlapping ADHD symptoms in autism: Relationship to executive functioning. Presented at the $2^{\text {nd }}$ International Meeting for Autism Research, Orlando, FL.

Folstein, S. E., Dowd, M., Winklosky, B., Tager-Flusberg, H., Tadevosyan, O. (2001). Likert Scales Based on a Factor Analysis of the Autism Diagnostic Interview. Presented at the $1^{\text {st }}$ International Meeting for Autism Research, San Diego, CA.

\section{SERVICE AND PROFESSIONAL AFFILIATIONS}

Ad hoc reviewer for Psychiatry Research; Psychological Assessment; The American Journal on Mental Retardation; European Journal of Paediatric Neurology American Psychological Association

Association for the Advancement of Behavior Therapy

\section{HONORS AND AWARDS}

University Fellow, University of Louisville

2002-2004

Beaty Memorial Scholarship, Allegheny College

1997-1998

Alden Scholar, Allegheny College

Freedom Support Act Scholarship, US Department of State

1996-1997 